\title{
Shift of annual water balance in the Budyko space for catchments with groundwater-dependent evapotranspiration
}

\author{
Xu-Sheng Wang ${ }^{1}$ and Yangxiao Zhou ${ }^{2}$ \\ ${ }^{1}$ Ministry of Education Key Laboratory of Groundwater Circulation and Evolution, China University \\ of Geosciences, Beijing 100083, China \\ ${ }^{2}$ UNESCO-IHE Institute for Water Education, Delft, the Netherlands
}

Correspondence to: Xu-Sheng Wang (wxsh@cugb.edu.cn)

Received: 8 October 2015 - Published in Hydrol. Earth Syst. Sci. Discuss.: 4 November 2015

Revised: 28 July 2016 - Accepted: 2 August 2016 - Published: 8 September 2016

\begin{abstract}
The Budyko framework represents the general relationship between the evapotranspiration ratio $(F)$ and the aridity index $(\varphi)$ for the mean annual steady-state water balance at the catchment scale. It is interesting to investigate whether this standard $F-\varphi$ space can also be applied to capture the shift of annual water balance in catchments with varying dryness. Previous studies have made significant progress in incorporating the storage effect into the Budyko framework for the non-steady conditions, whereas the role of groundwater-dependent evapotranspiration was not investigated. This study investigates how groundwater-dependent evapotranspiration causes the shift of the annual water balance in the standard Budyko space. A widely used monthly hydrological model, the ABCD model, is modified to incorporate groundwater-dependent evapotranspiration into the zone with a shallow water table and delayed groundwater recharge into the zone with a deep water table. This model is applied in six catchments in the Erdos Plateau, China, to estimate the actual annual evapotranspiration. Results show that the variations in the annual $F$ value with the aridity index do not satisfy the standard Budyko formulas. The shift of the annual water balance in the standard Budyko space is a combination of the Budyko-type response in the deep groundwater zone and the quasi-energy limited condition in the shallow groundwater zone. Excess evapotranspiration $(F>1)$ could occur in dry years, which is contributed by the significant supply of groundwater for evapotranspiration. Use of groundwater for irrigation can increase the frequency of the $F>1$ cases.
\end{abstract}

\section{Introduction}

Estimating catchment water balance is one of the fundamental tasks in hydrology. Efforts have long been devoted to construct the physical, empirical, and statistical models to explain the general relationship between precipitation $(P)$, runoff $(Q)$, potential evapotranspiration $\left(E_{0}\right)$ and actual evapotranspiration $(E)$ in terms of mean annual fluxes at the catchment scale (Budyko, 1948, 1958, 1974; Mezentsev, 1955; Fu, 1981; Porporato et al., 2004; Yang et al., 2008; Gerrits et al., 2009). A simple and highly intuitive approach widely used for estimating $E$ at the mean annual steady state is the Budyko framework, in which the mean annual evapotranspiration ratio $(E / P)$ was presumed to be a function of the climatic dryness:

$$
\frac{E}{P}=F\left(\frac{E_{0}}{P}\right)=F(\varphi)
$$

where $\varphi$ is the aridity index defined as $E_{0} / P$, and $F(\varphi)$ is an empirical function that relates $E / P$ to $\varphi$ based on general water-energy balance. The proposed formula by Budyko $(1958,1974)$ was

$$
F(\varphi)=\sqrt{\varphi[1-\exp (-\varphi)] \tanh (1 / \varphi)},
$$

which indicates a nonlinear relation between $F$ and $\varphi$. This $F-\varphi$ curve has been called the Budyko curve (Zhang et al., 2004; Roderick and Farquhar, 2011) and the $F-\varphi$ space was called the Budyko space (Renner et al., 2012).

Instead of using a single curve determined by Eq. (2) in the Budyko space, researchers have introduced a specific catchment parameter in $F(\varphi)$ to consider the impacts of catchment 
properties such as soils and vegetation (Mezentsev, 1955; Fu, 1981; Zhang et al., 2001). For example, Fu's equation (Fu, 1981) was derived following the idea of Mezentsev (1955), which can be expressed as follows:

$F(\varphi, w)=1+\varphi-\left(1+\varphi^{w}\right)^{1 / w}$,

where $w$ is a parameter representing the catchment conditions. $F$ increases with $w$, leading to reduced $Q / P$ as $w$ grows ( $\mathrm{Fu}, 1981)$. Fu's equation has been widely used in the last decade (Zhang et al., 2004, 2008; Yang et al., 2006, 2007; Greve et al., 2015). Donohue et al. (2007) highlighted the role of vegetation dynamics in the application of the Budyko framework. Wang and Tang (2014) also developed a oneparameter Budyko model based on the proportionality hypothesis and revealed a complex relationship between the catchment-specific parameter and the remote sensing vegetation index. These modified formulas suggested a group of Budyko curves instead of the single original Budyko curve, in which a curve represents a specific type of catchments with similar features controlling the mean annual water balance. Nevertheless, Gentine et al. (2012) argued that the original Budyko curve reflects the interdependence among vegetation, soil and climate, and could be applied as a strong constraint on land-surface parameterizations.

The Budyko hypothesis has been directly used to analyze the interannual change in water balance in catchments (Koster and Suarez, 1999; Arora, 2002; Zhang et al., 2008; Potter and Zhang, 2009), ignoring the change in storage $(\Delta S)$ under the assumption of steady-state water balance. One can plot annually the estimated $F$ data in the standard Budyko space to check whether the standard Budyko curves are sufficient or not to represent the interannual variability of evapotranspiration with the varying dryness. In this way, Potter and Zhang (2009) found that the Budyko framework is generally applicable for the catchments in Australia and that the optimal Budyko curve of the annual $F-\varphi$ data is highly dependent on the seasonal variations in rainfall. However, this approach should be carefully used when the annual $F$ value is approximated by the annual $(P-Q) / P$ value. Wang et al. (2009) and Istanbulluoglu et al. (2012) reported that the annual data of $(P-Q) / P$ in some basins are negatively related to the aridity index, exhibiting an inverse relation in comparison with the standard Budyko curves. According to long-term groundwater observations in the North Loup River basin, Nebraska, USA, Istanbulluoglu et al. (2012) demonstrated that the annual $F$ data estimated by $(P-Q-\Delta G) / P$ basically follow the Budyko hypothesis, where $\Delta G$ is the change in groundwater storage. However, in some other studies, an unexpected high evapotranspiration ratio $(F>1)$ was observed (Cheng et al., 2011; Wang, 2012; Chen et al., 2013). Among the 12 watersheds investigated by Wang (2012), half of them had such high $F$ values in 2 or more drought years. The physical base of the phenomena is the significant contribution of storage in dry periods by which the high level of evapotranspiration is maintained. Although some of the cases were triggered by extracting groundwater for irrigation in farmlands (Cheng et al., 2011; Wang, 2012), it could occur in natural conditions as a result of the temporal redistribution of water from seasonal patterns (Chen et al., 2013). Wang (2012) and Chen et al. (2013) proposed an approach to extend the Budyko framework for annual or even intraannual water balance by considering the soil water storage as a potential source of water supply for evapotranspiration. They defined $P-\Delta S$ for the selected timescales as the effective rainfall in building the modified Budyko space with $E /(P-\Delta S)$ and $E_{0} /(P-\Delta S)$, instead of $E / P$ and $\varphi$, respectively. In summary, the previous studies made significant progress in incorporating storage effects into the Budyko framework, but the role of groundwater-dependent evapotranspiration was not yet investigated.

The excess annual evapotranspiration may have originated from both soil water and groundwater. As reported by Wang (2012), during the drought year in 1988, two watersheds in Illinois, USA, showed $F=1.1$ with $\sim 100 \mathrm{~mm}$ depletion in soil water and $\sim 200 \mathrm{~mm}$ decrease in groundwater storage, respectively. It seemed that the contribution of groundwater was more significant (partially enhanced by groundwater pumping). A small depth to water table is an advantage to keep a high level of soil water content near the ground surface for evapotranspiration (Chen and $\mathrm{Hu}, 2004$ ). Therefore, it could be argued that the existence of shallow groundwater in a catchment would enhance the occurrence of the $F>1$ cases in drought years. Groundwater-dependent evapotranspiration at the regional scale has been noticed in the previous studies (York et al, 2002; Chen and $\mathrm{Hu}, 2004$; Cohen et al., 2006; Yeh and Famiglietti, 2009). Nevertheless, little has been known on the role of groundwater in the interannual variability of the evapotranspiration ratio with the varying dryness. Chen et al. (2013) did not identify the change in groundwater storage to explain the controls of the $F>1$ cases. Wang (2012) mentioned the potential role of groundwater in occurrence of the $F>1$ cases, but the individual contribution of groundwater-dependent evapotranspiration was not soundly analyzed.

This study develops a method to analyze the effect of groundwater-dependent evapotranspiration on the annual water balance of catchments in the standard Budyko space, in addition to the storage effect that was proposed in previous studies. In Sect. 2, the location, characteristics and data of the typical six studied catchments in the Erdos Plateau, China, are presented. Preliminary analysis showed the abnormal $F-\varphi$ relations in some of the catchments, which probably indicates the effect of groundwater-dependent evapotranspiration. In Sect. 3, a monthly hydrological model is developed from the widely used ABCD model (Thomas, 1981) to incorporate the groundwater-dependent evapotranspiration as well as the deep infiltration in the vadose zone. The monthly $E$ is partitioned into two components in accounting for the individual roles of the normal soil water-dependent and specific groundwater-dependent evapotranspiration. Then, the modi- 


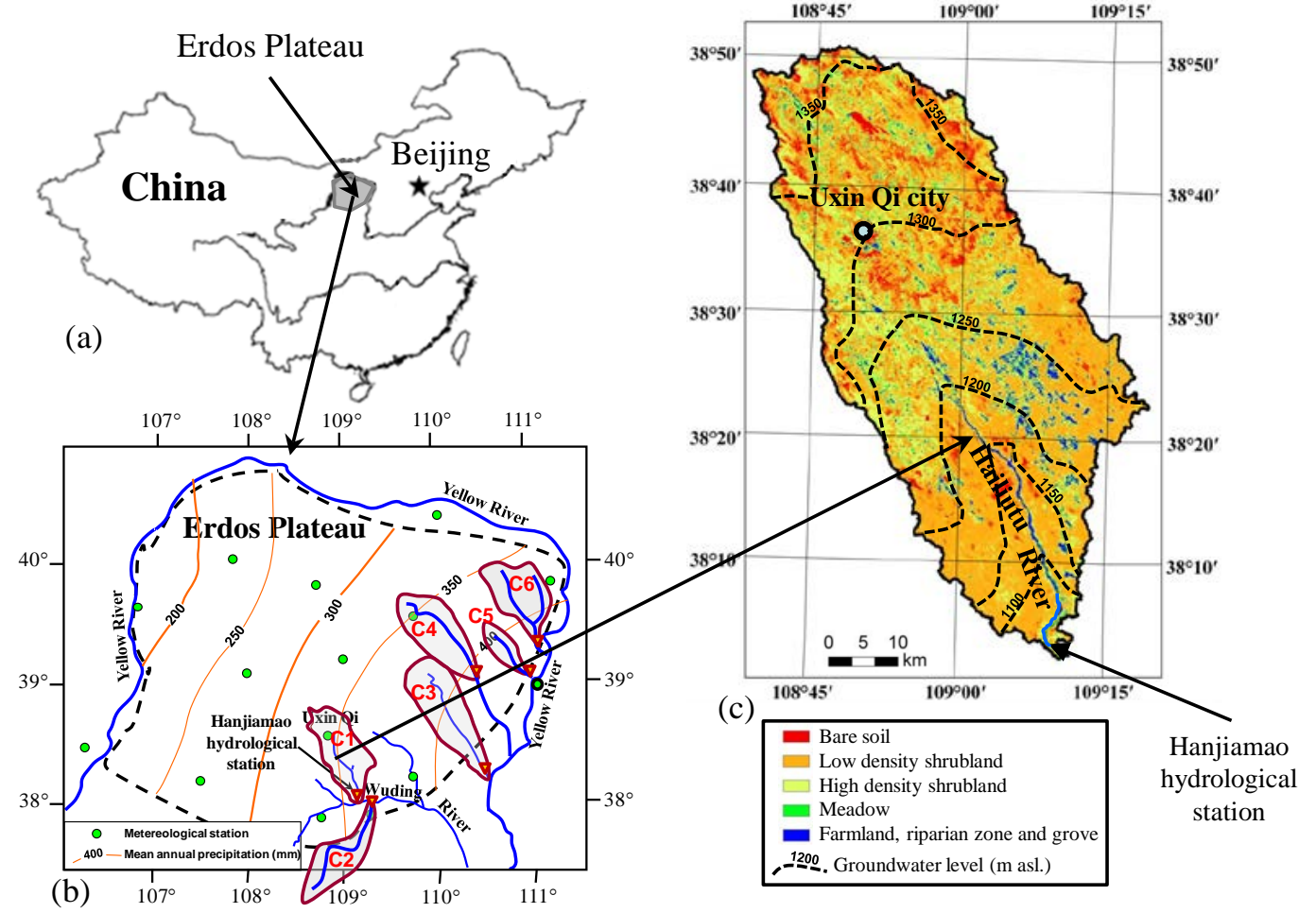

Figure 1. Geographic information of the study site: (a) location of the study area in northern-central China; (b) distribution of meteorological stations in the Erdos Plateau (green points) and the study catchments numbered C1-C6. (c) Characteristics of landscape in catchment C1 (the Hailiutu River catchment) according to Lv et al. (2013).

fied model is calibrated for the study catchments in Sect. 4 and used to produce the annual time series of the evapotranspiration components linking with the variable soil water and groundwater storages. With varying climatic dryness, the shifts of the interannual water balance in the standard and modified Budyko spaces are analyzed and discussed in Sect. 5. The impacts of human activities and the limitations of the approach are also discussed in Sect. 5.

\section{Study area, data and preliminary analysis}

\subsection{River basins}

The study area is located in the Erdos Plateau in northerncentral China (Fig. 1a), and belongs to the middle part of the Yellow River basin. The climate of the Erdos Plateau is typically inland semiarid to arid with a significant gradient of the mean annual precipitation, from $150 \mathrm{~mm}$ in the west to $450 \mathrm{~mm}$ in the east (Fig. 1b). More than half of the annual precipitation is received in the warm season (from June to September). Six catchments with available data, numbered C1-C6 (Fig. 1b), are selected for this study. The areas of the catchments range between 1272 and $3253 \mathrm{~km}^{2}$.

In particular, $\mathrm{C} 1$ is the Hailiutu River catchment, with an area of $2645 \mathrm{~km}^{2}$, which lies on the southeastern edge of the Mu Us Desert and is a sub-catchment of the Wuding River basin (Fig. 1b). The main channel in $\mathrm{C} 1$ has a length of approximately $85 \mathrm{~km}$ and flows southwards to the Hanjiamao hydrological station, as shown in Fig. 1c. Due to the arid climate and desert landscape, the land cover within the catchment is characterized by desert sand dunes with patches of mostly shrublands. Depression areas and terraces with shallow groundwater are covered by meadows and some farmlands. Wind-breaking trees (Salix matsudana and Populus tomentosa) can be found along the roads and crop areas. Farmlands are mainly located in the southern area and especially in the river valley. Crops cover only $\sim 3 \%$ of the total catchment area. Maize is the dominant crop and is irrigated with streamflow and/or groundwater. Several diversion dams have been constructed along the Hailiutu River for irrigation since the early 1970 s.

The other catchments have different characteristics. C2 is also located in the Wuding River basin, but is mainly covered by loess soils and shows a hillier landscape than that in $\mathrm{C} 1$. The landscape of $\mathrm{C} 3$ is a mixture of the desert sand dunes in the west and the loess hills in the east. C4-C6 are mainly located in the loess hills region with steep slopes and deep valleys. Among them, $\mathrm{C} 4$ is the upstream area of a larger river basin with more flat landscape than the downstream topography. A lot of ravines exist in the loess hills region by which floods can be released into the rivers. Soil and wa- 
Table 1. The characteristics of the study catchments shown in Fig. 1.

\begin{tabular}{lccccc}
\hline \multirow{2}{*}{ Catchments } & Area $\left(\mathrm{km}^{2}\right)$ & \multicolumn{4}{c}{ Mean annual flux* } \\
\cline { 3 - 6 } & & $P(\mathrm{~mm})$ & $E_{0}(\mathrm{~mm})$ & $Q(\mathrm{~mm})$ & Baseflow index \\
\hline C1 & 2645 & 367 & 1245 & 37.7 & 0.88 \\
C2 & 2415 & 386 & 1218 & 38.8 & 0.64 \\
C3 & 3253 & 447 & 1162 & 127.2 & 0.72 \\
C4 & 3065 & 381 & 1227 & 75.8 & 0.31 \\
C5 & 1272 & 466 & 1146 & 81.8 & 0.13 \\
C6 & 3246 & 412 & 1186 & 53.0 & 0.16 \\
\hline
\end{tabular}

* According to the data in the 1957-1978 period.

ter conservation projects have been conducted to control the floods and sediment loss. A comparison of the hydrological behaviors between $\mathrm{C} 1$ and $\mathrm{C} 6$ has been presented by Zhou et al. (2015). In the western part of the Erdos Plateau there are also some river basins, but they lack hydrological data for a proper analysis.

In the study area, groundwater is stored in complex aquifer systems. In general, the Erdos Plateau is characterized by shallow groundwater in the sandy sediments and deep groundwater in the underlying sandstones. In $\mathrm{C} 1-\mathrm{C} 2$, the Cretaceous sandstones form a thick aquifer enabling active groundwater circulation. In C3-C6, the Cretaceous sandstones are limited or replaced by the Jurassic sandstonemudstone formations with lower permeability so that the movement of deep groundwater is restricted. Meanwhile, shallow groundwater exists in the valleys or near-lake areas covered by sandy or loess sediments. Regional groundwaterlevel distribution in catchment $\mathrm{C} 1$ has been investigated in Lv et al. (2013) based on a hydrogeological survey carried out in 2010 and was shown in Fig. 1c. According to this investigation, the depth to water table (DWT) in $\mathrm{C} 1$ varies in a large range from zero to $110 \mathrm{~m}$. In more than half of the area, DWT is less than $10 \mathrm{~m}$. The shallow groundwater zone, where DWT is no more than $2 \mathrm{~m}$, occupies $16.0 \%$ of the whole catchment area. As investigated in Yin et al. (2015) at a research site in this catchment, when DWT is less than $2 \mathrm{~m}$, the actual evapotranspiration is generally $80 \%$ higher than the potential evapotranspiration. This investigation confirmed that groundwater-dependent evapotranspiration is an essential process in the Erdos Plateau.

\subsection{Data}

Daily streamflow data since 1957 for the hydrological stations at the outlets of the six catchments were collected from the Yellow River Conservancy Commission (YRCC, 2013). A rainfall gauge was also installed at the Hanjiamao hydrological station (Fig. 1c) in 1961, providing daily precipitation.

To better account for the variability of rainfall in space and time, we develop gridded monthly precipitation data with $1 \mathrm{~km}$ resolution between 1957 and 2010 from the data of 15 national meteorological stations in the Erdos Plateau (Fig. 1b). Monthly rainfall data at these stations were downloaded from the China Meteorological Administration (CMA, 2012). We construct the gridded data using the inverse distance square weighting (IDSW) method due to the moderate topography of the Erdos Plateau in the form of lowrelief rolling hills. Fig. 1b shows the mean annual precipitation contours of the Erdos Plateau obtained from the gridded data. In this study, the area-averaged monthly data of the precipitation in the six catchments for the period 1957-2010 are estimated by imposing the basin boundaries on the gridded monthly precipitation data and taking the arithmetic average of the cell values within the catchment.

The method applied in constructing the gridded precipitation data is further applied in constructing a $1 \mathrm{~km}$ resolution gridded data set for the monthly pan evaporation between 1957 and 2010 covering the Erdos Plateau. The pan evaporation data were based on observations from $200 \mathrm{~mm}$ diameter pans that were installed in most stations in the Erdos Plateau, and can also be downloaded from the CMA dataset (CMA, 2012). The average monthly data of the potential evapotranspiration $\left(E_{0}\right)$ in the six catchments are estimated from the spatially averaged data of the pan evaporation using a local pan coefficient $(0.58)$ for the $200 \mathrm{~mm}$ diameter pan. This coefficient was suggested by various investigations of pan coefficients for Chinese meteorological stations (Shi et al., 1986; Fan et al., 2006).

In summary, the mean annual values of $P, E_{0}$ and $Q$ during the period in 1957-1978 for the six catchments are listed in Table 1. In this period, the streamflow was not significantly influenced by the hydraulic engineering, irrigation water use and coal mine industry, so that the hydrological behavior was close to the natural state. It can be estimated from the data that the mean annual $Q / P$ values in this "natural" state ranged between 0.1 and 0.3 for the catchments. Accordingly, the mean annual $F$ values are higher than 0.7 with respect to the mean values of the aridity index $\left(E_{0} / P\right)$ varying between 2.5 and 3.4 .

In Fig. 2a, the variation patterns of the monthly rainfall and potential evapotranspiration during 1957-2010 are shown for 


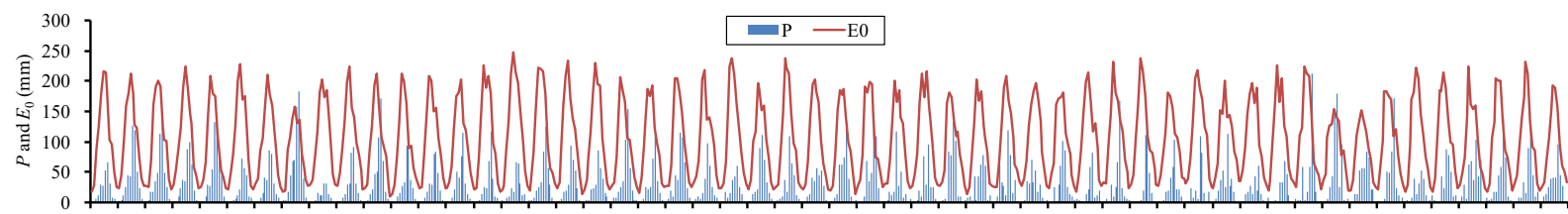

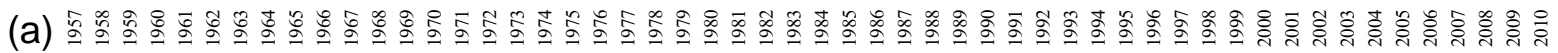

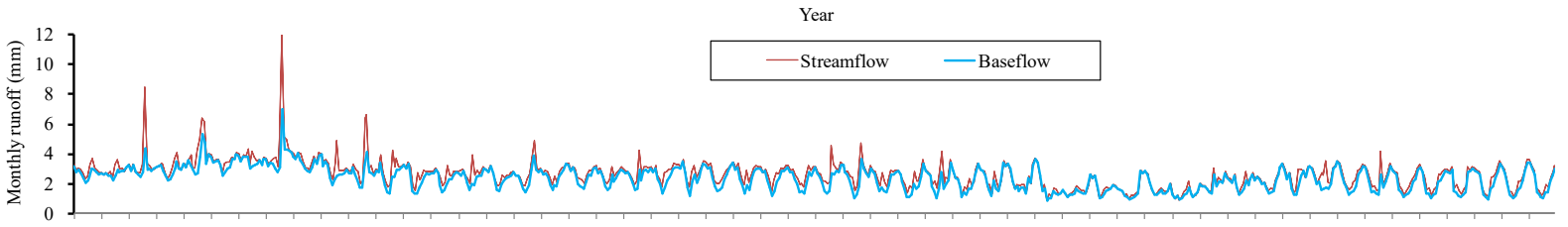

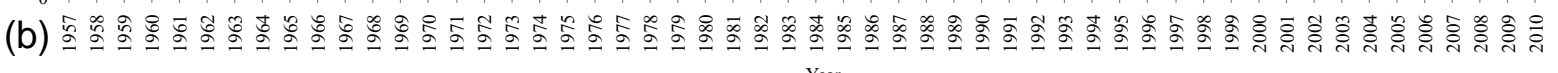

Year

Figure 2. The monthly meteorological data (a) and streamflow-baseflow data (b) from 1957 to 2010 in catchment C1.

Table 2. Mean annual fluxes in the Hailiutu River catchment (C1) in different periods.

\begin{tabular}{lccrr}
\hline Periods & $\begin{array}{c}P \\
(\mathrm{~mm})\end{array}$ & $\begin{array}{c}E_{0} \\
(\mathrm{~mm})\end{array}$ & $\begin{array}{c}Q \\
(\mathrm{~mm})\end{array}$ & $\begin{array}{r}\text { Number Of } \\
\text { diversions } \\
\text { (reservoirs)* }\end{array}$ \\
\hline $1957-1966$ & 387.0 & 1230.2 & 42.3 & $0(0)$ \\
$1967-1987$ & 337.0 & 1269.6 & 32.6 & $4(2)$ \\
$1988-1997$ & 329.9 & 1240.2 & 23.4 & $9(2)$ \\
$1998-2010$ & 352.8 & 1234.0 & 28.0 & $10(2)$ \\
\hline
\end{tabular}

* According to Yang et al. (2012).

catchment $\mathrm{C} 1$. Both rainfall and evapotranspiration are high in the summer and low in the winter. However, there is a difference in the patterns by which the seasonal variation in runoff may be influenced: the rainfall peak normally arrives in August, but the highest evaporation is exhibited in June. With respect to these meteorological patterns, the total runoff drops in the spring and in the early summer until the heavy rainfall comes in August, as shown in Fig. 2b. In comparison with the rainfall and the potential evapotranspiration, the mean monthly runoff $(2.6 \mathrm{~mm})$ and its fluctuation amplitude $(0.8-11.9 \mathrm{~mm})$ are quite small. This indicates that most of the precipitation in $\mathrm{C} 1$ returns to the atmosphere by evapotranspiration. During 1957-2010, the annual aridity index in the catchment showed a large variation range (between 1 and 10), covering the semi-humid, semi-arid and arid climatic conditions as classified in the scheme recommended by the United Nations Environment Programme (UNEP) (Middleton and Thomas, 1992).

In the study area, there are significant interannual fluctuations in streamflow. For catchment C1, Yang et al. (2012) investigated the annual regime shifts in streamflow and found that the shifts were caused largely by land use policy changes and river water diversions for irrigation. Table 2 shows the mean annual fluxes in four typical periods with different numbers of water diversions in the Hailiutu River and major branches during 1957-2010. These diversions influenced the hydrological behavior in $\mathrm{C} 1$ and will be discussed in the following sections. However, before 1967, the Hailiutu River was free of hydraulic engineering, and the studied area was mostly close to the natural conditions. In the other catchments, the changes in the streamflow regime were also mainly contributed by human activities but in more complex ways. In C6, the river discharge was also influenced by a large number of check dams that were constructed to reduce water and sediment loss (Zhou et al., 2015). In C3-C5, the impacts of the coal mining industry were significant. To analyze the natural hydrological behaviors, the study period should not be later than 1978 .

\subsection{Preliminary analysis using $(P-Q) / P$}

In many cases, it is possible to estimate the annual $E$ in a catchment from the annually observed $P$ and $Q$ by $P-Q$ when the change in storage is significantly small. Then it could be treated as the "real" data of the annual $E$ and the shift of annual water balance in the Budyko space could be investigated with the plot of $(P-Q) / P$ vs. $\varphi$. In this section, we check the validity of this approach in the study area.

The plots of annual $(P-Q) / P$ vs. $\varphi$ during $1957-1878$ (close to the natural state) for the six catchments are shown in Fig. 3. In particular, Fig. 3a shows the locations of the mean annual $(P-Q) / P$ data of the six catchments in the Budyko space. The data points fall below the original Budyko curve given by Eq. (2), but can be bounded between two modified Budyko curves that are determined using Eq. (3). They approximately exhibit a positive relation between $(P-Q) / P$ and $\varphi$. This indicates that the behaviors of the catchments on a long-term average (22 years) satisfied the steady-state water balance assumption in the original Budyko framework.

If the original Budyko formula (Budyko, 1958) is available for the annual water balance, the annual $(P-Q) / P$ value should be equal to $F(\varphi)$, so that the shift path of $(P-Q) / P$ 

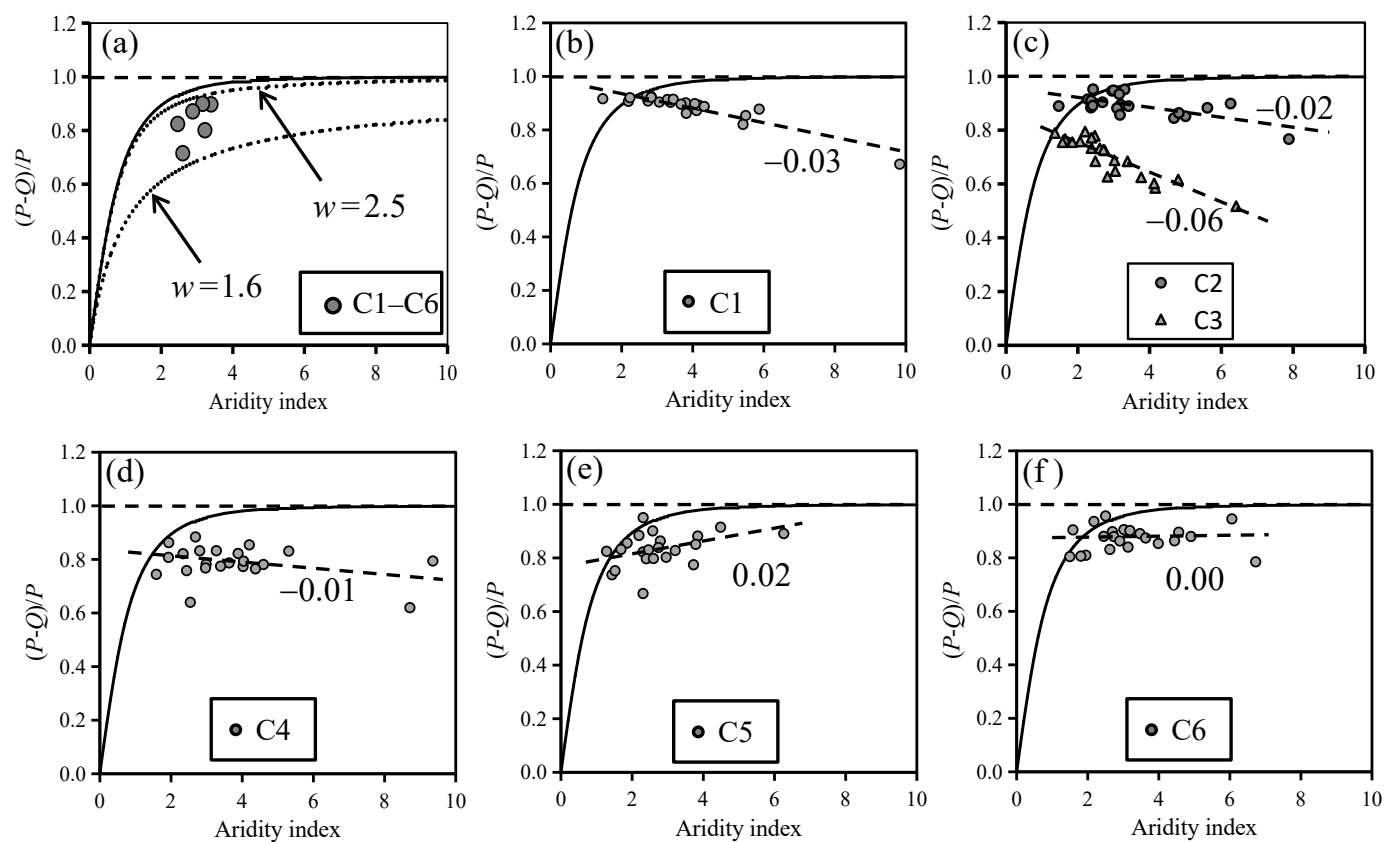

Figure 3. The plots of the annual $(P-Q) / P$ data vs. the aridity index in the study catchments for the 1957-1978 period: (a) the mean annual data points for the six catchments bounded by the two Budyko curves (dashed lines) according to Eq. (3) with $w=1.6$ and $w=2.5$; and (b-f) are the annual data points of the different catchments. C1-C6 are the numbers of the catchments shown in Fig. 1. The solid line is the original Budyko curve determined with Eq. (2). The dashed lines are the regression curves of the scatter data points with the slope values shown nearby.

in each catchment should be an increasing curve with a positive slope in the Budyko space. However, as shown in Fig. 3b-d, the annual $(P-Q) / P$ data in $\mathrm{C} 1-\mathrm{C} 4$ follow a negative relation. The annual $(P-Q) / P$ value of $\mathrm{C} 3$ significantly decreased from $\sim 0.8$ to $\sim 0.5$ when the aridity index increased from 1.2 to 5.8 (Fig. 3c). It seems that C5 (Fig. 3e) and C6 (Fig. 3f) showed a positive relation, but the data points did not fall closely along the original Budyko curve. The negative relations in $\mathrm{C} 1-\mathrm{C} 4$ are contrary to the positive relation in the original Budyko framework, indicating the falseness of taking the annual $(P-Q) / P$ as the replica of the annual $F$ value in the study area. In a previous study, Istanbulluoglu et al. (2012) also highlighted this abnormal relation in the North Loup River basin, Nebraska, USA, and they demonstrated that it was caused by ignoring the change in storage. They used long-term monitoring data of groundwater level to estimate the interannual change in groundwater storage $(\Delta G)$ and replaced the $(P-Q) / P$ data with the $(P-Q-\Delta G) / P$ data to reproduce a normal Budyko curve for the basin. However, groundwater-dependent evapotranspiration was not explicitly considered in Istanbulluoglu et al. (2012).

It is a good idea to estimate the change in groundwater storage using groundwater monitoring data. However, longterm groundwater-level monitoring data are not available for the catchments in this study. In addition, the approach of using $(P-Q-\Delta G) / P$ data ignores the interannual change in the soil moisture storage. In a different way from Istanbulluoglu et al. (2012), we estimate $\Delta G$ from the monthly baseflow (groundwater discharge) data with a calibrated hydrological model, into which the groundwater-dependent evapotranspiration is also incorporated. Using the model, the storage components and the contribution of groundwater for the annual $E$ can be simultaneously obtained at the catchment scale.

\section{Hydroclimatologic models}

\subsection{The ABCD model}

The ABCD model is a conceptual hydrological model with four parameters $(a, b, c$, and $d$ ) developed by Thomas (1981) to account for the actual evapotranspiration, surface/subsurface runoff and storage changes. The ABCD model was originally applied at an annual time step but has been recommended as a monthly hydrological model (Alley, 1984). It was widely applied as a hydroclimatologic model to investigate the response of catchments to climate change (Vandewiele et al., 1992; Fernandez et al., 2000; Sankarasubramanian and Vogel, 2002; Li and Sankarasubramanian, 2012).

Both the soil water and groundwater are considered in the ABCD model, as shown in Fig. 4a. At the monthly time step, the change in the soil water storage is determined by 


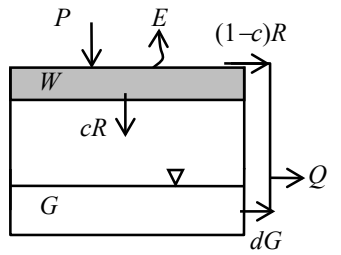

(a)

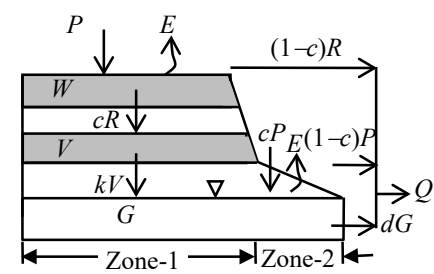

(b)
Figure 4. Schematic representations of the ABCD model (a) and ABCD-GE model (b). $W$ and $V$ are the effective soil water storage and the effective storage in the transition vadose zone, respectively. $G$ is the effective groundwater storage.

$W_{\mathrm{m}}-W_{\mathrm{m}-1}=P_{\mathrm{m}}-E_{\mathrm{m}}-R_{\mathrm{m}}$,

where $W_{\mathrm{m}-1}$ and $W_{\mathrm{m}}$ are the effective soil water storages at the beginning and at the end of the $m$ th month, respectively; $P_{\mathrm{m}}$ and $E_{\mathrm{m}}$ are the monthly precipitation and evapotranspiration, respectively; and $R_{\mathrm{m}}$ is the monthly loss of soil water via direct runoff and groundwater recharge. The change in groundwater storage is determined by

$G_{\mathrm{m}}-G_{\mathrm{m}-1}=c R_{\mathrm{m}}-\mathrm{d} G_{\mathrm{m}}$,

where $G_{\mathrm{m}-1}$ and $G_{\mathrm{m}}$ represent the groundwater storage at the beginning and end of the $m$ th month, respectively; $c$ and $d$ are two parameters that account for groundwater recharge and discharge from $R_{\mathrm{m}}$ and $G_{\mathrm{m}}$, respectively. The monthly streamflow is the summation of the monthly direct runoff and groundwater discharge, as follows:

$Q_{\mathrm{m}}=(1-c) R_{\mathrm{m}}+\mathrm{d} G_{\mathrm{m}}$.

The change in storage in the ABCD model is the summation of the changes in the soil water storage and groundwater storage, which can be expressed as $\left(W_{\mathrm{m}}-W_{\mathrm{m}-1}\right)+\left(G_{\mathrm{m}}-G_{\mathrm{m}-1}\right)$.

Thomas (1981) proposed a nonlinear function to estimate $\left(E_{\mathrm{m}}+W_{\mathrm{m}}\right)$ from $\left(P_{\mathrm{m}}+W_{\mathrm{m}-1}\right)$ as follows:

$E_{\mathrm{m}}+W_{\mathrm{m}}=\frac{P_{\mathrm{m}}+W_{\mathrm{m}-1}+b}{2 a}$

$-\sqrt{\left(\frac{P_{\mathrm{m}}+W_{\mathrm{m}-1}+b}{2 a}\right)^{2}-\frac{\left(P_{\mathrm{m}}+W_{\mathrm{m}-1}\right) b}{a}}$,

where $a$ is a dimensionless parameter and $b$ is the upper limit of $\left(E_{\mathrm{m}}+W_{\mathrm{m}}\right)$. In addition, Thomas (1981) assumed that

$W_{\mathrm{m}}=\left(E_{\mathrm{m}}+W_{\mathrm{m}}\right) \exp \left(-E_{0 \mathrm{~m}} / b\right)$

where $E_{0 \mathrm{~m}}$ is the monthly potential evaporation for the $m$ th month. Substituting Eq. (8) into Eq. (7), the monthly evapo- transpiration can be estimated as

$$
\begin{aligned}
& E_{\mathrm{m}}=\left[\frac{P_{\mathrm{m}}+W_{\mathrm{m}-1}+b}{2 a}\right. \\
& \left.-\sqrt{\left(\frac{P_{\mathrm{m}}+W_{\mathrm{m}-1}+b}{2 a}\right)^{2}-\frac{\left(P_{\mathrm{m}}+W_{\mathrm{m}-1}\right) b}{a}}\right] \\
& {\left[1-\exp \left(-\frac{E_{0 \mathrm{~m}}}{b}\right)\right] .}
\end{aligned}
$$

Wang and Tang (2014) demonstrated that Eq. (9) can be derived from the generalized proportionality principle and yield an equivalent Budyko-type model.

\subsection{The ABCD-GE model}

To investigate the effect of groundwater-dependent evapotranspiration in basins with both shallow and deep groundwater, the original $A B C D$ model is extended in this study as the ABCD-GE model, where "GE" denotes groundwaterdependent evapotranspiration. As shown in Fig. 4b, a catchment is conceptually divided into two zones where Zone-1 and Zone-2 represent different areas with deep and shallow groundwater, respectively. Direct runoff originates from both zones. Surface water (water in river, canals, lakes, etc.) is also included in Zone-2. The soil water reservoir in Zone-1 is the same as that in the ABCD model. In addition, a transition vadose zone is specified between the soil layer and water table to represent the delayed groundwater recharge. The transition zone is included to handle the existence of the thick unsaturated zone $(>10 \mathrm{~m})$ in a basin. Soil water in this zone is dominated by the vertical downward flow. In Zone-2, the rainfall and evapotranspiration are the components directly involved in the water balance of groundwater. Thus, three storage components are considered as a chain in the hydrological processes. It is assumed that the potential change in groundwater storage by the lateral flow coming in and out of a catchment is negligible. For a large river basin $\left(>1000 \mathrm{~km}^{2}\right)$ this assumption is generally acceptable.

Dividing Zone-1 and Zone-2 in a catchment depends on how groundwater can be accessed by the evapotranspiration process. It is controlled by the depth of plant roots and the rise of capillary water above the water table. In the case study of catchment $\mathrm{C} 1$, it was observed that some trees have long roots that penetrated $2-3 \mathrm{~m}$ or more into the soil ( $\mathrm{Lv}$ et al., 2013), but in general the dominant root zone is less than $2 \mathrm{~m}$ below the ground surface for shrubs and grasses. When the DWT is larger than $2 \mathrm{~m}$, the contribution of groundwater for evapotranspiration will dramatically decrease to a negligible level (Yin et al., 2015). Thus, it is reasonable to use the contours of $2 \mathrm{~m}$ depth of groundwater as the approximate boundary between Zone- 1 and Zone- 2 in the study area. In Zone-1, the transition vadose zone is roughly defined as the zone between $2 \mathrm{~m}$ depth below the ground surface and $2 \mathrm{~m}$ height above the water table. In the assumptions of the ABCD- 
GE model, this zone could not be influenced by both the evapotranspiration and groundwater flow processes. Thus, the thickness of the soil layer would be less than $2 \mathrm{~m}$ in the model. However, one should be aware that it is not necessary to find the distinct and exact boundaries for the zones, since the ABCD-GE model is a conceptual hydrological model.

Similar to that in the ABCD model, the change in the soil water storage in Zone-1 is determined by

$W_{\mathrm{m}}-W_{\mathrm{m}-1}=P_{\mathrm{m}}-E_{1 \mathrm{~m}}-R_{\mathrm{m}}$,

where $E_{1 \mathrm{~m}}$ is the monthly evapotranspiration in Zone-1 determined with Eq. (9); $R_{\mathrm{m}}$ becomes the summation of the leaking soil water to the transition vadose zone, $c R_{\mathrm{m}}$, and the direct runoff, $(1-c) R_{\mathrm{m}}$, in Zone-1. The change in storage of the vadose zone is described with

$V_{\mathrm{m}}-V_{\mathrm{m}-1}=c R_{\mathrm{m}}-k V_{\mathrm{m}}$,

where $V_{\mathrm{m}}$ and $V_{\mathrm{m}-1}$ represent the values of the storage in the transition vadose zone at the end and beginning of the $m$ th month, respectively, and $k$ is the parameter that accounts for the groundwater recharge rate as $k V_{\mathrm{m}}$.

In the ABCD-GE model, the source of runoff is partitioned by the fractions of the area of the two zones. The total runoff in the catchment is the summation of the direct runoff and groundwater discharge as follows:

$Q_{\mathrm{m}}=(1-\alpha)(1-c) R_{\mathrm{m}}+\alpha(1-c) P_{\mathrm{m}}+\mathrm{d} G_{\mathrm{m}}$,

where $\alpha$ is the ratio of the Zone-2 area to the whole catchment area. In Eq. (12), the term $(1-\alpha)(1-c) R_{\mathrm{m}}$ denotes the direct runoff contributed by Zone-1, whereas the term $\alpha(1-c) P_{\mathrm{m}}$ denotes the direct runoff contributed by Zone2 . In considering the gain-loss processes of groundwater, the change in the effective groundwater storage is yielded by

$G_{\mathrm{m}}-G_{\mathrm{m}-1}=(1-\alpha) k V_{\mathrm{m}}+\alpha\left(c P_{\mathrm{m}}-E_{2 \mathrm{~m}}\right)-\mathrm{d} G_{\mathrm{m}}$,

where $E_{2 \mathrm{~m}}$ is the monthly evapotranspiration in Zone-2, which depends on the effective groundwater storage as follows:

$E_{2 \mathrm{~m}}=g G_{\mathrm{m}} E_{0 \mathrm{~m}}$,

where $g$ is a parameter controlling the intensity of groundwater-dependent evapotranspiration. Eq. (14) assumes that the evapotranspiration rate in Zone- 2 is simply proportional to both the groundwater storage (which is positively related to groundwater level) and the potential evapotranspiration rate. Thus, the evapotranspiration rate as a whole in the catchment is summarized as

$E_{\mathrm{m}}=(1-\alpha) E_{1 \mathrm{~m}}+\alpha E_{2 \mathrm{~m}}$.

Eqs. (10)-(13) are solved one by one and finally the value of $G_{\mathrm{m}}$ is substituted into Eq. (12) to obtain the runoff. The results of the ABCD-GE model are controlled by seven parameters as $a, b, c, d, g, k$ and $\alpha$. The parameter values can be identified with the model calibration process.

\section{Model calibration and results}

\subsection{Model calibration}

We apply the ABCD-GE model to estimate the monthly evapotranspiration and the change in the storage components in the six catchments after the model parameters were calibrated. The monthly evapotranspiration data are then summed up to estimate the annual evapotranspiration for further analysis. The model calibration is based on the observed monthly streamflow data at the hydrological stations and the separated baseflow data.

Because groundwater discharge has been included in the model, a baseflow analysis was performed to obtain the expected groundwater discharge for the model calibration. Using the HYSEP automated hydrograph separation method (Sloto and Crouse, 1996) on the daily streamflow data, such "observed" groundwater discharge data were obtained. For C1, these data were partly reported in Zhou et al. (2013). The mean values of the baseflow index for $\mathrm{C} 1-\mathrm{C} 6$ range between 0.13 and 0.88 (Table 1). Catchment $\mathrm{C} 1$ has the highest baseflow index (0.88), indicating that groundwater discharge is the dominant hydrological process in this catchment. Variation patterns of the monthly groundwater discharge in $\mathrm{C} 1$ are shown in Fig. 2b. In C5 and C6, the baseflow index values are smaller than 0.2 because most of the streamflow in the two catchments is contributed by direct runoff.

The ordinary least squares (OLS) criterion is applied for parameter estimation. The errors of both log-streamflow and log-baseflow were included in the OLS objective function, as follows:

$\min U=\sum_{\mathrm{m}=1}^{N}\left(e_{\mathrm{m}}^{2}+q_{\mathrm{m}}^{2}\right)$,

where

$e_{\mathrm{m}}=\ln (\hat{Q} / Q)_{\mathrm{m}}, q_{\mathrm{m}}=\ln \left(\hat{Q}_{\mathrm{b}} / Q_{\mathrm{b}}\right)_{\mathrm{m}}$

and $U$ is the value of the objective function; $N$ is the number of the months; $\hat{Q}$ and $Q$ are the simulated and observed monthly streamflow, respectively; $\hat{Q}_{\mathrm{b}}$ is the simulated monthly groundwater discharge through $\mathrm{d} G_{\mathrm{m}}$ in Eq. (12); and $Q_{\mathrm{b}}$ is the "observed" monthly groundwater discharge obtained from the baseflow analysis. The log form errors given in Eq. (17) are used to obtain the homoscedastic residuals (rather than the residual errors) of the normal absolute differences between the observed data and the model outputs (Alley, 1984). The generalized reduced gradient (GRG) (Lasdon et al., 1978) nonlinear optimization algorithm is applied to determine the optimum values of the parameters. The NashSutcliffe efficiency (NSE) (Nash and Sutcliffe, 1970) is also used to evaluate the performance of the model in simulating the monthly runoff. It ranges in $(-\infty, 1)$, whereas a higher than zero value is required for a well-performed model. 
For catchment $\mathrm{C} 1$, the model parameters are firstly identified using the 1957-1966 data, and this calibrated model is considered to be a "natural" model due to the minimum impact of human activities during this 10 -year period. For C2C6, the 1957-1978 period is applied to roughly identify the "natural" model. The initial storage values are treated as the unknown parameters to be determined in the calibration process. Changes in the initial conditions generally influenced the simulated results in the first and second years. Therefore, the residual errors in the later years are applied to estimate the parameter values with less influence from the initial conditions. A sensitivity analysis is carried out to schematically capture the ranges of the parameter values.

The best fitting parameter values of the "natural" models for $\mathrm{C} 1-\mathrm{C} 6$ are shown in Table 3. The $a$ value ranges between 0.91 and 0.97. In previous studies using the $\mathrm{ABCD}$ model, the $a$ value was generally found to be higher than 0.9 (Alley, 1984; Sankarasubramanian and Vogel, 2002; Li and Sankarasubramanian, 2012). The $b$ and $c$ values in this study are generally higher than those obtained by Alley (1984) for 10 catchments in the USA. The higher $c$ value indicates the more significant role of groundwater in the hydrological behaviors. However, the $d$ values of $\mathrm{C} 1-\mathrm{C} 6$ fall into the range suggested by Alley (1984). The optimized $\alpha$ values in the "natural" models range between 0.09 and 0.27. In particular, the $\alpha$ value of $\mathrm{C} 1(0.21)$ in this "natural" state was larger than the current value (DWT in $16.0 \%$ of the area is less than $2 \mathrm{~m})$. Such a difference is reasonable because the groundwater level in the 1950s and 1960s should be higher than that at present, as indicated by the higher baseflow (Fig. 2b). The $k$ value controls the rate of groundwater recharge below the transition vadose zone. The transition vadose zone is a necessary component in $\mathrm{C} 1-\mathrm{C} 3$, as demonstrated by the sensitivity analysis. When an extremely high value of $k$ is used $(k>100)$, the $k V_{\mathrm{m}}$ value would be almost equal to $c R_{\mathrm{m}}$, so that the transition vadose zone does not make sense. However, in this situation the model could not capture the seasonal variation patterns of groundwater discharge. Thus, the delayed groundwater recharge is an essential process for the catchments. The best fitting $k$ values for $\mathrm{C} 4-\mathrm{C} 6$ are significantly higher than those for $\mathrm{C} 1-\mathrm{C} 3$, indicating a weaker delay effect. This confirms the hydrogeological conditions in C4-C6: active groundwater flow is limited in the near-surface zone.

For the calibration period, the root-mean-square error (RMSE) of the "natural" models with respect to the aggregated results of the six catchments is $39 \%$ for the monthly runoff. For the aggregated annual runoff data, the RMSE is $21 \%$. The errors include the streamflow observation error and the meteorological data treatment error. It is more reasonable to evaluate the model performance according to the observation-simulation correlation coefficient and the NSE value. A comparison between the observed and simulated monthly runoff (including groundwater discharge) for all of the six catchments can be seen in Fig. 5. The coefficient of determination $\left(\mathrm{R}^{2}=0.89\right)$ is high. The NSE val-

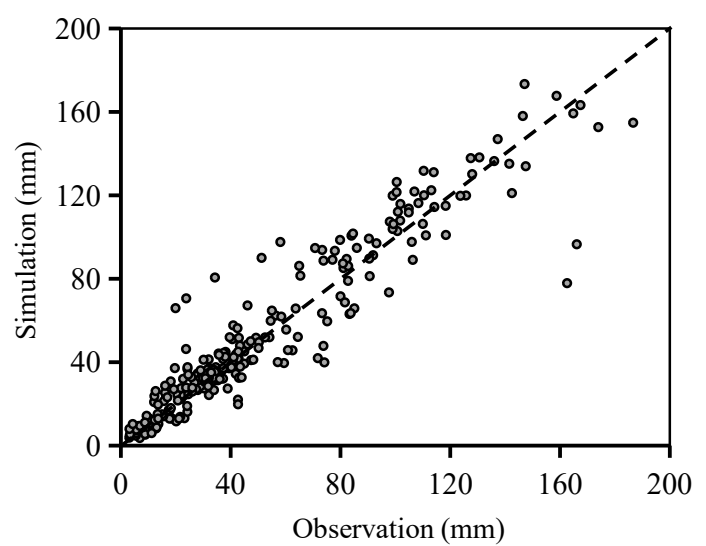

Figure 5. Scatter plot for the observation and simulation results of the monthly runoff and groundwater discharge in the study catchments in the calibration period.

ues of the model range between 0.48 and 0.81 for the different catchments (Table 3), indicating that the model performs well in the study area. It is usually difficult to obtain a high NSE value for a catchment with weak seasonal variation in runoff (Mathevet et al., 2006), such as that in C1 and C2.

\subsection{Modeling results}

We use the "natural" models to estimate the monthly hydrological components during the whole 1957-2010 period. As an example, typical results of catchment $\mathrm{C} 1$ are shown in Fig. 6. The modeling results of the monthly runoff after the 1970s are generally higher than the observed data (Fig. 6a) due to one ignoring the impacts of land use changes and increased utilization of water for irrigation. However, the simulated patterns of groundwater discharge are similar to the observations (Fig. 6b): falling in the summer, rising in the winter. This agreement between the simulated and observed patterns demonstrates the ability of the ABCD-GE model in simulating the hydrological behaviors in the studied catchment: significant groundwater-dependent evapotranspiration occurs in the summer, and a strong recovery of storage in the shallow-groundwater zone occurs in the winter due to delayed recharge from the thick vadose zone.

For catchment $\mathrm{C} 1$, there are significant differences between the observed and model-calculated annual runoff after 1966, as shown in Fig. 6c. This deviation could be interpreted as the excess evapotranspiration induced by the increasing agricultural water use. Enhanced evapotranspiration also occurred in the shallow groundwater zone due to groundwater pumping for irrigation. To evaluate the actual water balance, the following equation,

$E_{\mathrm{ACT}} \approx E_{\mathrm{NAT}}+\left(Q_{\mathrm{NAT}}-Q_{\mathrm{OBS}}\right)$,

is applied to approximately estimate the actual annual evapotranspiration $\left(E_{\mathrm{ACT}}\right)$ after 1966 from the "natural" model 
Table 3. Best fitting parameters of the "natural" models for the study catchments.

\begin{tabular}{lcrccccccc}
\hline Catchments & $a$ & $b(\mathrm{~mm})$ & $c$ & $d$ & $\mathrm{~g}$ & $k$ & $\alpha$ & $\alpha g G_{\text {mean }} *$ & NSE \\
\hline C1 & 0.97 & 33 & 0.97 & 0.05 & 0.010 & 0.017 & 0.21 & 0.14 & 0.51 \\
C2 & 0.91 & 75 & 0.92 & 0.11 & 0.058 & 0.025 & 0.09 & 0.12 & 0.43 \\
C3 & 0.91 & 41 & 0.90 & 0.18 & 0.017 & 0.017 & 0.18 & 0.15 & 0.71 \\
C4 & 0.94 & 83 & 0.68 & 0.19 & 0.049 & 0.076 & 0.21 & 0.09 & 0.67 \\
C5 & 0.97 & 155 & 0.67 & 0.10 & 0.070 & 0.214 & 0.27 & 0.14 & 0.81 \\
C6 & 0.93 & 179 & 0.67 & 0.11 & 0.077 & 0.162 & 0.18 & 0.11 & 0.71 \\
\hline
\end{tabular}

* Gmean is the mean value of the effective groundwater storage in the calibration period.
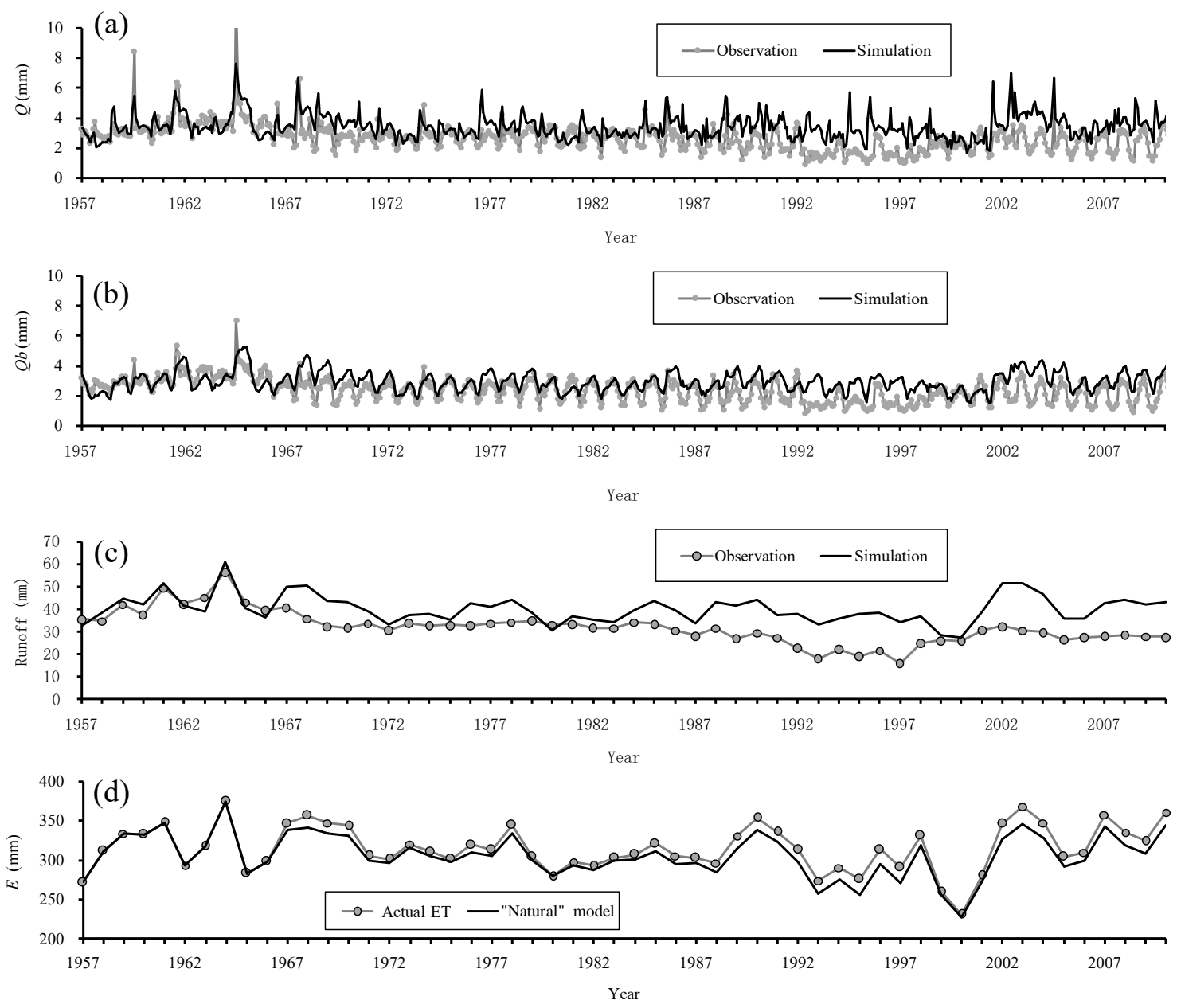

Figure 6. Simulated results of the "natural" ABCD-GE model in comparison with the observation data in catchment C1 from 1957 to 2010 , including monthly runoff (a), groundwater discharge (b), annual runoff (c) and annual evapotranspiration (d). The actual evapotranspiration in (d) was estimated with Eq. (18).

result $\left(E_{\mathrm{NAT}}\right)$ plus the difference of the annual runoff between the "natural" model $\left(Q_{\mathrm{NAT}}\right)$ and the observation ( $\left.Q_{\text {OBS }}\right)$. This difference may be partly induced by the multiple timescale variations in the climate conditions, but would be mainly caused by the irrigation water use. Results are shown in Fig. 6d. It seems that the relative difference between $E_{\mathrm{NAT}}$ and $E_{\mathrm{ACT}}$ is not significant. The maximum
$Q_{\mathrm{NAT}}-Q_{\mathrm{OBS}}$ value is less than $10 \%$ of the mean annual evapotranspiration $(\sim 315 \mathrm{~mm})$. Accordingly, the irrigation water use in this catchment did not significantly influence the annual evapotranspiration. However, it dramatically influenced the streamflow. As shown in Fig. 6a, almost all of the direct runoff was removed from the total runoff after 1987 and the groundwater discharge was significantly de- 

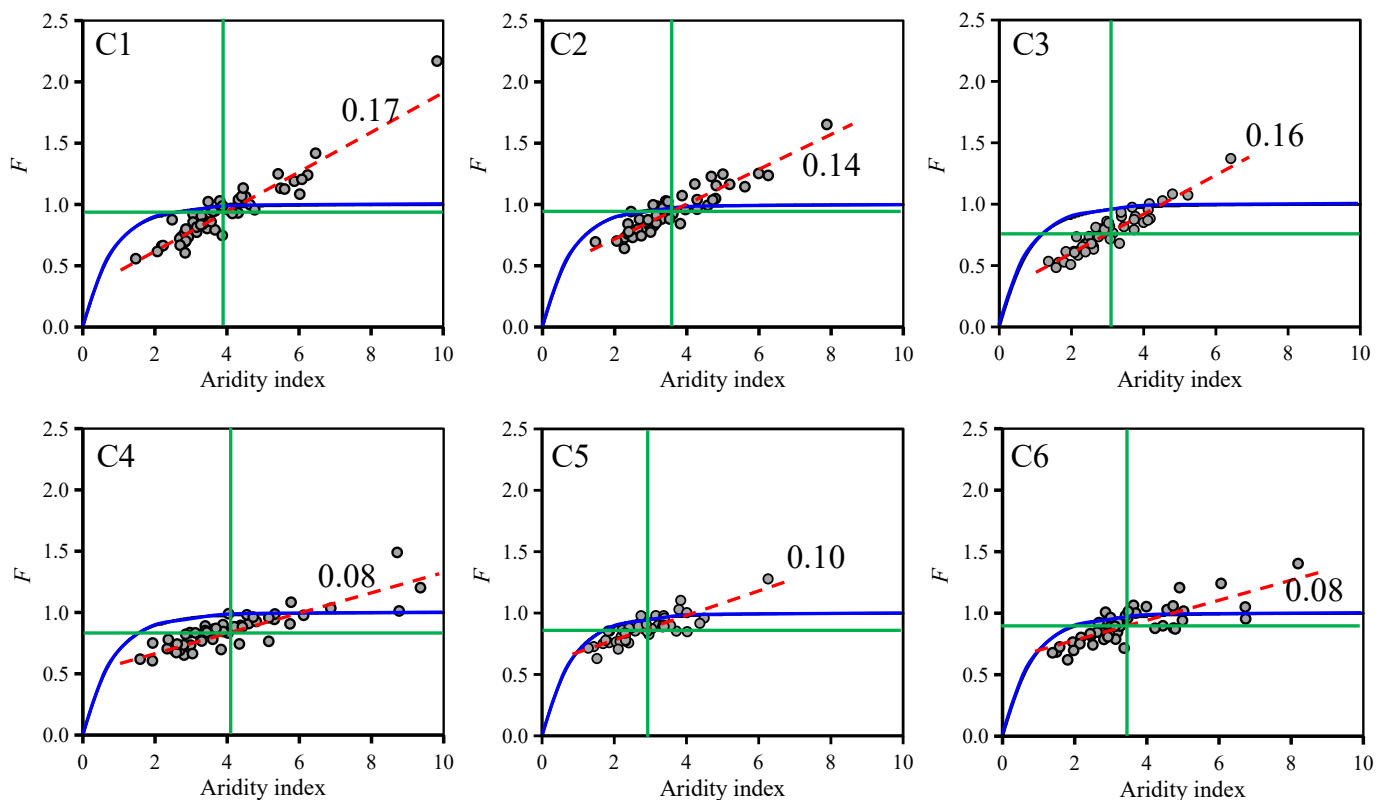

Figure 7. Plots of the annual $F-\varphi$ data in the study catchments in the standard Budyko space for the 1957-2010 period. The actual evapotranspiration is estimated using the "natural" models. The solid blue line is the original Budyko curve determined with Eq. (2). The dashed red lines are the linear regression curves of the data points with the slope data shown nearby. The intersection point of the green lines denotes the mean annual data.

creased even though the seasonal patterns basically remained (Fig. 6b).

\subsection{Annual water balance in the standard Budyko space}

In Fig. 7, the annual $F$ data for the annual water balance obtained from the "natural" models over the 1957-2010 period are plotted in the standard Budyko space. It is obvious that with the increasing aridity index $(\varphi)$, the evapotranspiration ratio $(F)$ for all of the catchments increased in almost a linear pattern with the different slopes. When $\varphi<4$, most of the data points fall below the original Budyko curve, indicating that $F<1$ is generally satisfied in this situation. When $\varphi>4$, the original Budyko curve gives $F \approx 1$, indicating the limitation $(0<F \leq 1)$ for the mean annual evapotranspiration ratio. However, some of the data points fall above the line of $F=1$, while $\varphi$ is larger than 3 but even less than 4 , indicating that the $F>1$ cases did not only occur in dry years. The maximum $F$ value (2.2) was obtained in $\mathrm{C} 1$ when the aridity index jumped from $\varphi=1.5$ in 1964 to $\varphi=9.8$ in 1965 . This means that $\mathrm{C} 1$ lost a volume of water in 1965 by evapotranspiration that is more than twice the gained water from precipitation in the same year. In comparison, the $F$ values in $\mathrm{C} 4$ and $\mathrm{C} 6$ are not sensitive to the change in the aridity index since the slopes of the $F-\varphi$ regression lines are less than 0.1 .

The effect of groundwater-dependent evapotranspiration can be clearly observed when the evapotranspiration ratio is divided into two parts and plotted in the Budyko space separately with respect to the shallow and deep groundwater zones. The annual $E$ values in Zone-1 and Zone-2 are estimated, respectively, as

$E_{1}=\sum_{\mathrm{m}=1}^{12} E_{1 \mathrm{~m}}\left(W_{\mathrm{m}-1}, a, b\right)$ and $E_{2}=\sum_{\mathrm{m}=1}^{12} E_{2 \mathrm{~m}}\left(G_{\mathrm{m}}, g\right)$

for every year, where $E_{1 \mathrm{~m}}$ is calculated with Eq. (9), whereas $E_{2 \mathrm{~m}}$ is calculated with Eq. (14). Typical results are shown in Fig. 8 for $\mathrm{C} 1$ and $\mathrm{C} 4$. The data in Fig. 8 are estimated with the parameter values of $a, b$ and $g$ for the "natural" models. It is obvious that the annual $E_{1} / P$ values in Zone-1 (deep groundwater) for the whole range of the aridity index $(0<\varphi<8)$ are smaller than 1.0 and fall below the original Budyko curve determined by Eq. (2). The low $E_{1} / P$ value in Zone-1 is mainly due to the water-limited condition in the soils without the supply of groundwater, especially in $\mathrm{C}$ 1, where the landscape is dominated by sand dunes. The variation of $E_{1} / P$ can be approximately fitted by the Budyko curve determined with Eq. (3) using $w=1.4$ and 1.6, respectively, for $\mathrm{C} 1$ and $\mathrm{C} 4$. The higher $w$ value in $\mathrm{C} 4$ is linked with the higher $b$ value of the model for $\mathrm{C} 4$, as listed in Table 3. However, the relationship between $E_{2} / P$ and the annual aridity index in the shallow groundwater zone definitely could not be explained by any of the standard Budyko formulas, because for Zone-2 all the annual $F$ values are higher than 1.0 in $\mathrm{C} 1$ and most of the data points fall above the bound in $\mathrm{C} 4$. 

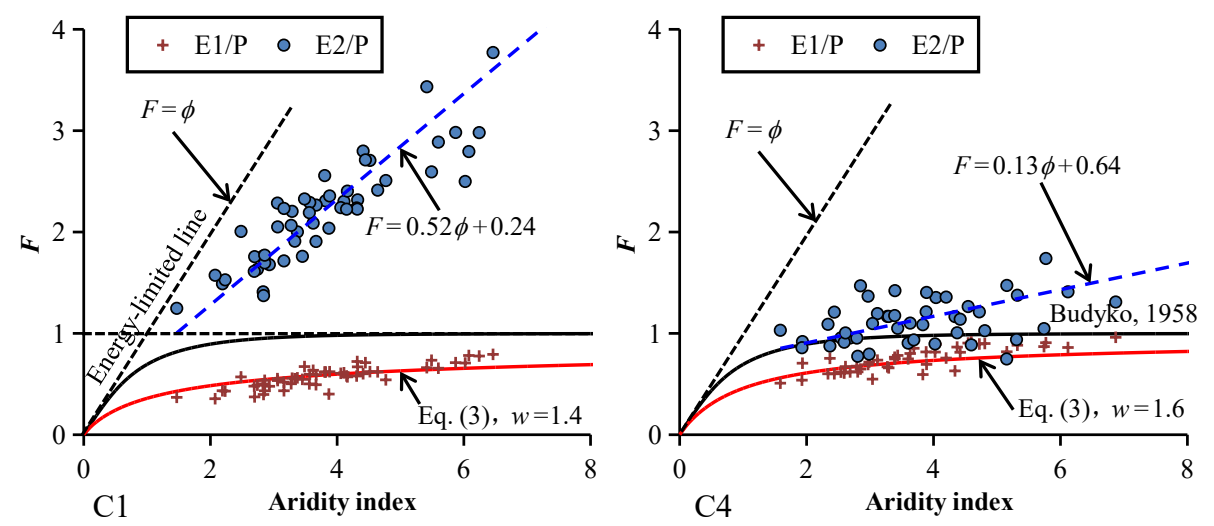

Figure 8. Plots of the $F-\varphi$ data in the standard Budyko space using the $E_{1}$ data for Zone-1 and the $E_{2}$ data for Zone-2 that estimated with Eq. (19) in catchments C1 (left) and C4 (right). The red curves are the Budyko curves determined with Eq. (3), which could approximately represent the variations of the $E_{1} / P$ data. The dashed blue lines are the linear regression lines of the $E_{2} / P$ data.

In catchment $\mathrm{C} 1$, the $E_{2} / P$ data points follow a linear regression line with a slope of 0.52 . This agrees with the relationship between $E_{2}$ and $E_{0}\left(E_{2} \propto E_{0}\right)$ that is described in Eq. (14). Since the groundwater storage, $G$, is relatively stable (small $d$ and $k$ values in the model), the annual $E_{2} / P$ value would be proportional to the $\varphi$ value and the slope is close to the annual mean value of $g G$. In $\mathrm{C} 1$, the annual mean value of $g G$ is 0.65 according to the "natural" model. Such a groundwater-dependent evapotranspiration process is the reason for the occurrence of the $F>1$ cases at the catchment scale. Note that in the original Budyko framework, the $F=\varphi$ case denotes an energy-limited condition when water supply (only precipitation for mean annual water balance) is sufficient for the evapotranspiration process. The slope of the $E_{2} / P$ line in $\mathrm{C} 1$ is less than 1.0, but is closer to the $F=\varphi$ line than the water-limited line represented by $F=1$. It indicates that in Zone- 2 the evapotranspiration process is in a quasi-energy-limited condition, rather than in a water-limited condition, because shallow groundwater can effectively serve as an external source of water supply.

In $\mathrm{C} 4$, the $E_{2} / P$ data points show a scatter distribution around the regression line. This is mainly caused by the significant variability in the groundwater storage, $G$, at the monthly and annual scales. The $d$ and $k$ values in the model for $\mathrm{C} 4$ are quite larger than that for $\mathrm{C} 1$ by which the model could capture the significant fluctuation of the baseflow. As a result, the annual mean $g G$ values of $\mathrm{C} 4$ vary in a large range between 0.18 and 0.84 . Similar unstable $E_{2} / P$ data also exist for $\mathrm{C} 5$ and $\mathrm{C} 6$ as indicated by the high $d$ and $k$ values (Table 3).

\section{Discussions}

\subsection{Controls on the $F>1$ cases}

It has been demonstrated in Fig. 7 that the annual evapotranspiration ratio, $F$, could be higher than 1.0 when the aridity index, $\varphi$, is larger than 4.0 in the studied catchments. In the literature, the $F>1$ cases were also observed when $\varphi$ is just higher than 1.0 (Cheng et al., 2011; Wang, 2012; Chen et al., 2013). Thus, it is interesting to discuss how the occurrence of the $F>1$ cases is controlled by the catchment properties when shallow groundwater plays an important role.

The equation for the annual evapotranspiration ratio can be derived from Eqs. (15) and 19) as follows:

$F=(1-\alpha) \frac{E_{1}}{P}+\alpha g \frac{E_{0}}{P} \sum_{\mathrm{m}=1}^{12}\left(\frac{E_{0 \mathrm{~m}}}{E_{0}} G_{\mathrm{m}}\right)$,

where the term $E_{0 \mathrm{~m}} / E_{0}$ denotes the proportion of the monthly potential evaporation to the annual one with respect to the $m$ th month. It has been known that the relationship between $E_{1} / P$ and $\varphi$ determined by the ABCD model is similar to that predicted by the standard Budyko formulas, as shown in Fig. 8, where $E_{1} / P$ is less than 1.0. For the groundwater-dependent term, defining

$G_{a}=\sum_{\mathrm{m}=1}^{12}\left(\frac{E_{0 \mathrm{~m}}}{E_{0}} G_{\mathrm{m}}\right)$

as the weighted average of the monthly groundwater storage, Eq. (20) can be replaced by

$F(\varphi)=(1-\alpha)\left[1+\varphi-\left(1+\varphi^{w}\right)^{1 / w}\right]+\alpha g G_{a} \varphi$,

where $E_{1} / P$ is represented by Eq. (3). According to Eq. (22), the function $F(\varphi)$ is controlled by the parameters, $g, w, \alpha$ and the status of groundwater represented by $G_{a}$. As indicated in Eq. (14), $g G_{a}$ is a dimensionless parameter to de- 

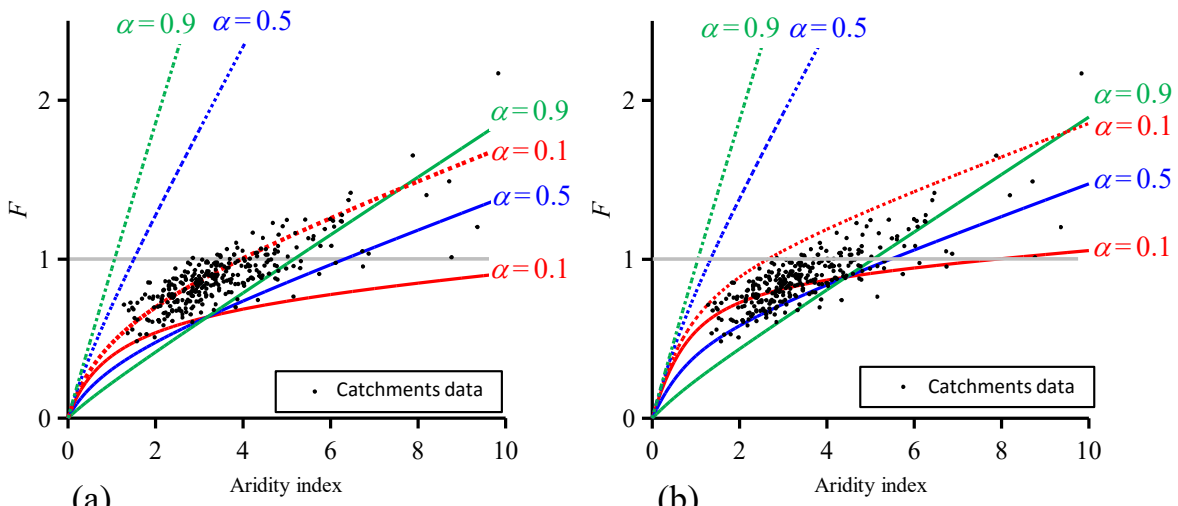

Figure 9. The typical $F-\varphi$ curves for annual water balance in the standard Budyko space determined with Eq. (22) when $w=1.5$ (a) and $w=2.0$ (b). The solid and dashed curves are estimated using $g G_{a}=0.2$ and $g G_{a}=1.0$, respectively. Dots are the data points of the study catchments.

scribe the intensity of groundwater-dependent evapotranspiration related to the potential evaporation. The recommended range of $g G_{a}$ is $0.2-1.0$ according to Table 3. In Eq. (22), the term with $w$ indicates the normal energy-water-limited process in Zone-1, whereas the term with $g G_{a}$ indicates the quasi-energy-limited process in Zone-2. The actual $F$ value is a mixed result of the different processes.

Typical $F-\varphi$ curves obtained with Eq. (22) are plotted in Fig. 9. It can be seen that the proportion of shallow water table area $(\alpha)$ has a large effect on the occurrence of the $F>1$ case. When the shallow water table area is small ( $\alpha=0.1$ ), the $F>1$ case occurs only during dry years. When the $g G_{a}$ value increases, the $F>1$ case occurs at the smaller aridity index. The specific catchment parameter $(w)$ for $E_{1} / P$ also influences the occurrence of the $F>1$ case. A larger $w$ value shifts the $F-\varphi$ curves (comparing Fig. 9b with a) to the left side, indicating that the $F>1$ case could occur at the smaller aridity index.

Groundwater-dependent evapotranspiration estimated in the ABCD-GE model does not violate the $F<1$ rule for the long-term steady-state water balance, because the model will yield $E=P-Q$ for the average flux in a long-term period. As shown in Fig. 9, more than half of the data points fall below the line of $F=1$, indicating that the less-than- 1 rule for the average $F$ value is satisfied in the whole study area. For each catchment, in addition, the mean annual $F-\varphi$ data for the 1957-2010 period have been shown in Fig. 7 (intersection points of the green cross lines). None of these mean annual $F$ values is higher than 1 .

\subsection{Using effective precipitation and the modified Budyko space}

The standard Budyko space assumes that the potential water supply for evapotranspiration is only rainfall in a catchment. This is valid for the mean annual water balance, but exceptions might exist for the annual or intra-annual behaviors.
Several previous studies attempted to modify the Budyko framework for the short timescale. Wang (2012) and Chen et al. (2013) argued that the reduction of storage in a period should be regarded as one of the water supply components. They suggested an approach to replace the evapotranspiration ratio and the aridity index by $E /(P-\Delta S)$ and $E_{0} /(P-\Delta S)$, respectively, where $\Delta S$ is the storage depletion in a studied period and $P-\Delta S$ is regarded as the effective precipitation. In this modified Budyko space, evapotranspiration is always less than the water supply, so that the original Budyko hypothesis could be satisfied for the small timescale problems. Alternatively, Greve et al. (2016) proposed a two-parameter Budyko function to explain the cases of evapotranspiration exceeding precipitation in unsteadystate conditions. However, groundwater flow is not included in their model, so that the role of groundwater-dependent evapotranspiration could not be assessed by such a twoparameter Budyko function.

In this section, we attempt to check the characteristics of the annual water balance data in the study area using the modified Budyko space suggested by Wang (2012) and Chen et al. (2013). With the results of the ABCD-GE model, the total change in storage for a year can be estimated as

$$
\begin{aligned}
& \Delta S=\sum_{\mathrm{m}=1}^{12}\left[(1-\alpha)\left(W_{\mathrm{m}}+V_{\mathrm{m}}-W_{\mathrm{m}-1}-V_{\mathrm{m}-1}\right)\right. \\
& \left.+\left(G_{\mathrm{m}}-G_{\mathrm{m}-1}\right)\right]
\end{aligned}
$$

where $m$ is the number of the months in the year, $W_{0}, V_{0}$ and $G_{0}$ for $m=0$ denoting the respective storage components at the end of the previous year.

Results are shown in Fig. 10 for the six studied catchments. It can be seen that in the modified Budyko space the annual water balance data fall into the zone below the limitation: $E /(P-\Delta S)<1$. However, in any one of the catchments, the shift path of the data points could not be captured by a single Budyko curve in the modified Budyko space. For 

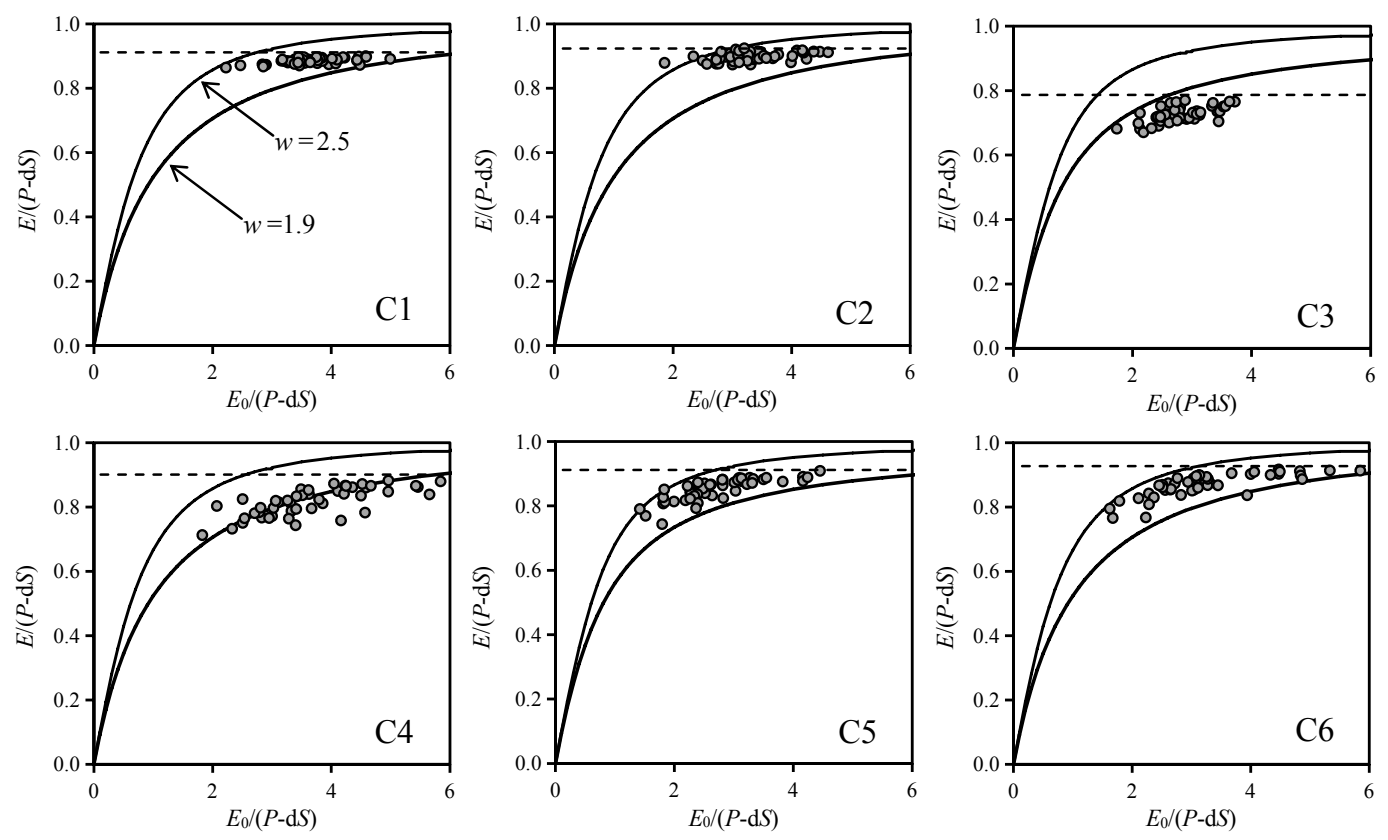

Figure 10. The annual water balance data in the modified Budyko space with the effective precipitation defined by Wang (2012). Dots are the data obtained for the catchments using the "natural" models. The solid curves represent the standard Budyko curves determined with Eq. (3) using $E_{0} /(P-\Delta S)$ and $E /(P-\Delta S)$, respectively, instead of $F$ and $\varphi$. Budyko curves of $w=1.9$ and $w=2.5$ are selected to bound the data points of catchment $\mathrm{C} 1$ and applied for the comparison with the other catchments. The dashed lines approximately represent the limitations of the $E /(P-\Delta S)$ data.

the cases in $\mathrm{C} 1$ and $\mathrm{C} 2$, the increase in $E /(P-\Delta S)$ with the increasing $E_{0} /(P-\Delta S)$ seems too small in comparison with any one of the standard Budyko curves determined by Eq. (3). A similar difference between the data and the standard Budyko curves also exists in the other catchments, but is not as significant as that in $\mathrm{C} 1$ and $\mathrm{C} 2$. Furthermore, in $\mathrm{C} 1$ and $\mathrm{C} 2$ the $E /(P-\Delta S)$ value approaches a stable value around 0.90 with the high $E_{0} /(P-\Delta S)$ values. It indicates that at least $10 \%$ of $P-\Delta S$ is contributed to the annual runoff in terms of $Q /(P-\Delta S)$. This portion of the water supply seems to be inaccessible for the evapotranspiration process. Similar bounds of the $E /(P-\Delta S)$ value also exist in C3-C6. In particular, this limitation is lower than 0.8 in $\mathrm{C} 3$, implying a significant contribution of change in storage to the streamflow in dry years.

The difficulties in using the effective precipitation defined by Wang (2012) and Chen et al. (2013) are the unknown $\Delta S$ for an investigated time step and the possible existence of the inaccessible part of $\Delta S$ for the evapotranspiration process. Consequently, the estimation of the $E /(P-\Delta S)$ value is not straightforward, but requires a complex iteration process. In the original Budyko framework for the steady-state water balance, the water supply (only precipitation) does not depend on both evapotranspiration and runoff, so that the aridity index is an independent variable in assessing the behaviors of the catchments. However, the water supply represented by the effective precipitation is influenced by the evapotranspiration-runoff processes due to the feedback mechanism. This interdependence between the water supply and evapotranspiration significantly reduces the efficiency of using the modified Budyko space in analyzing the shift of annual water balance in a catchment. In contrast, it would be an efficient and straightforward approach to extend formulas for annual water balance in the standard Budyko space, such as Eq. (22), keeping an independent index $(\varphi)$ for the climatic conditions.

\subsection{Landscape-driven and human-controlled shifts of annual water balance}

As illustrated in Fig. 6d, the actual evapotranspiration in catchment $\mathrm{C} 1$ has been enhanced by human activities. This impact might exist in both the shallow and deep groundwater zones. Crops in $\mathrm{C} 1$ are mainly planted in the depressions and terrace lands with shallow groundwater, especially in the river valley. Crops require much more water than the precipitation for growing. For example, maize could consume more than 3 times the rainfall water in growing seasons (Zhou et al., 2013). Thus, irrigation is necessary to maintain the agricultural production. In the croplands far away from the rivers, groundwater was abstracted from wells for irrigation. In the river valley, irrigation was realized with the diversions and channels. Therefore, an increase in the evapotranspiration in the shallow groundwater zone is dominated by irrigation. 
Along the river, the area of the surface water body was significantly enlarged in the reservoirs, leading to an increase in the surface water evapotranspiration loss. It is equivalent to the increase in groundwater-dependent evapotranspiration in this study because surface water is also included in the shallow groundwater zone. As a result, the shift of the annual water balance in the Budyko space was partly caused by change in land use and controlled by regulation of river water for irrigation.

Recently, Jaramillo and Destouni (2014) developed a method to assess the landscape-driven change in the mean evapotranspiration ratio using the difference between the actual change in the $F$ value and the climate-driven change in the $F$ value following the Budyko framework. In this section, we extend their method to assess the landscape-driven change in annual water balance in catchment $\mathrm{C} 1$. The period between 1957 and 1966 is selected from Table 2 as the reference period. Changes are evaluated for the different average values of the annual $F$ data in the different periods listed in Table 2. The climate-driven change is estimated with the annual $E_{\mathrm{NAT}}$ values obtained from the "natural" model, using a formula similar to Jaramillo and Destouni (2014), as follows:

$\Delta\left(\frac{E_{\mathrm{LD}}}{P}\right)=\Delta\left(\frac{E_{\mathrm{ACT}}}{P}\right)-\Delta\left(\frac{E_{\mathrm{NAT}}}{P}\right)$,

where $\Delta\left(E_{\mathrm{LD}} / P\right)$ denotes the landscape-driven change in comparison with the 1957-1966 period. However, this quantity index includes the landscape changes driven by both the climatic force and human activities. To check how this index is correlated with the increasing impacts from the reservoirs and diversions in rivers, following Jaramillo and Destouni (2015), the coefficient of intra-annual variation of the monthly runoff $\left(C V_{Q}\right)$ was applied. The $C V_{Q} / C V_{P}$ value was estimated to reveal the separate influence of such a human-controlled flow regulation from the mixed human-climate controlling, where $C V_{P}$ is the coefficient of intra-annual variation of the monthly rainfall.

Results of the $\Delta\left(E_{\mathrm{LD}} / P\right)$ and $\Delta\left(C V_{Q} / C V_{P}\right)$ data between the three periods 1968-1987, 1988-1997, and 1998-2010 and the reference period 1957-1967 are shown for catchment $\mathrm{C} 1$ in Fig. 11 . The $\Delta\left(E_{\mathrm{LD}} / P\right)$ values are all positive but not big (less than $6 \%$ ), indicating a slight increase in the evapotranspiration ratio after 1966 driven by the changes in the natural landscape conditions of water storage and/or human-controlled land use. The $\Delta\left(C V_{Q} /, C V_{P}\right)$ values show a significant fluctuation around zero, but are also limited in a small range $( \pm 5 \%)$. Both the $\Delta\left(E_{\mathrm{LD}} / P\right)$ and $\Delta\left(C V_{Q} / C V_{P}\right)$ values are largest in 1988-1997. Fluctuations of these data could not be fully explained by the increasing number of diversions in the rivers. The negative $\Delta\left(C V_{Q} / C V_{P}\right)$ value in $1968-1987$ may be caused by the construction of two reservoirs since reservoirs commonly smooth the variation of the streamflow. In 1988-1997, the $\Delta\left(C V_{Q} / C V_{P}\right)$ value became positive when five new diver-

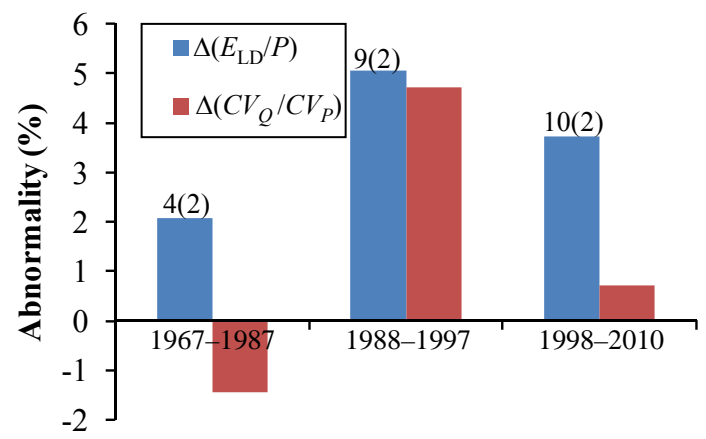

Figure 11. Histogram of the $\Delta\left(E_{\mathrm{LD}} / P\right)$ data determined with Eq. (24) and the $\Delta\left(C V_{Q} / C V_{P}\right)$ data determined with the coefficients of intra-annual variation of the monthly runoff $\left(C V_{Q}\right)$ and rainfall $\left(C V_{P}\right)$ for the different periods in catchment $\mathrm{C} 1$. The numbers of diversions (reservoirs) are shown on the top of the blocks according to Table 2 .

sions were built, indicating the opposite impacts of the reservoirs and diversions. It is possible that the streamflow was disturbed by the regulation of water for irrigation on these diversions with small overflow dams. The decrease in the $\triangle\left(C V_{Q} / C V_{P}\right)$ value from $4.72 \%$ in $1988-1977$ to $0.72 \%$ in 1998-2010 may be caused by the control of the river water use under some government policies to prevent desertification (Yang et al., 2012; Zhou et al., 2015). The following decrease in the $\Delta\left(E_{\mathrm{LD}} / P\right)$ value from $5.05 \%$ in $1988-1997$ to $3.73 \%$ in $1998-2010$ is not significant, seemingly indicating the alternative irrigation practice in the croplands (for example, pumping groundwater), so that the real water consumption was reduced but still on a high level. As a result, utilization of surface water and groundwater for irrigation can increase the frequency of the $F>1$ cases.

\subsection{Limitation remarks}

Attention should be paid to the simplifications in the conceptual model extended from the ABCD model, when the equations and formulas are applied in complicated catchments. The ABCD model assumes that the storageevapotranspiration relationship is controlled by the parameters $a$ and $b$, whereas the physical interpretation of them is difficult (Alley, 1984). Eq. (8) in the ABCD model is also hypothesized from a simplified storage-loss model that is controlled by the parameter $b$ (Thomas, 1981). Sankarasubramanian and Vogel (2002) suggested that the $b$ value for the annual water balance could be approximately represented by the maximum soil moisture field capacity plus the maximum $E_{0}$ for $\varphi<1$ or the maximum $P$ for $\varphi \geq 1$. The $a$ value is generally estimated in a small range between 0.95 and 1.0. In this study, the model output is not sensitive to the $a$ value. The correlation between $a$ and $b$ may exist because both of them are positively related to $E_{\mathrm{m}}+W_{\mathrm{m}}$ in Eq. (7). The ABCD model neglects the possibility of groundwater- 
dependent evapotranspiration that has been incorporated into the ABCD-GE model. The ABCD-GE model divides the area into shallow and deep groundwater zones, without considering a complicated spatial distribution of groundwater depth. For the shallow groundwater zone, the evapotranspiration is assumed to be proportional to the groundwater storage. Nonlinear behavior in groundwater-dependent evapotranspiration could be further included if it can be successfully parameterized. A linear groundwater storage-discharge relationship is adopted in both of the ABCD and ABCD-GE models. These simplifications could cause systematic errors in modeling a catchment where the nonlinear behaviors in the hydrological processes are significant.

Limitations in the data processing and complexities in the hydrogeological conditions could also influence the accuracy of the modeling results. The average potential evapotranspiration data, $E_{0}$, and the average precipitation data, $P$, in some degree, are dependent on the estimation methods and may introduce biases. For the hydrogeological conditions, this study assumed that the boundary of a catchment determined along the terrain divides is also the boundary of groundwater flow; i.e., no inter-basin transfer of groundwater exists. The assumption is plausibly acceptable in the eastern part of the Erdos Plateau because the spatial variation in the groundwater level is highly correlated with the land surface elevation in this area (Lv et al. 2013; Zhou et al., 2015). However, the groundwater flow system in the western part of the Erdos Plateau is more complex, where the climate is more arid and water table divides could be significantly different from the terrain divides.

In fact, when the Budyko framework is applied for small timescale water balance in a catchment, the other additional sources of water supply should be considered, apart from groundwater. Significant changes in soil moisture, snow cover or frozen water in cold regions could also cause an "abnormal" shift of the annual water balance for a catchment in the standard Budyko space (Jaramillo and Destouni, 2014). The effects of these storage components are negligible in this study, but may be essential in other study areas. In particular, the special processes in the cold regions are not included in the ABCD-GE model. However, one can refer to Martinez and Gupta (2010), where the snow-augmented ABCD model was proposed and can be incorporated into an extension of the ABCD-GE model.

\section{Conclusions}

The Budyko framework was developed for the long-term steady-state water balance in catchments, which estimates the evapotranspiration ratio $(F)$ as a function of the aridity index $(\varphi)$. It can be represented by curves for the $F-\varphi$ relationship in the standard Budyko space that were determined by the original Budyko formula without any parameter or the formulas with a catchment-specific parameter. It is interesting to investigate whether the Budyko space can also be ap- plied to capture the annual water balance in a catchment with varying dryness. However, the shift of the annual water balance in the standard Budyko space could be significantly different from that presumed from the standard Budyko curves, in particular, when the cases of $F>1$ occur as have been observed in a number of catchments.

In this study, we highlight the effect of groundwaterdependent evapotranspiration in triggering the abnormal shift of the annual water balance in the standard Budyko space. A conceptual monthly hydrological model, the ABCD-GE model, is developed from the widely used ABCD model to incorporate groundwater-dependent evapotranspiration into the zone with a shallow water table and delayed groundwater recharge into the zone with a deep water table. The model is successfully applied to analyze the behaviors of six catchments in the Erdos Plateau, China.

The results show that the standard Budyko formulas are not applicable for the interannual variability of catchment water balance when groundwater-dependent evapotranspiration is significant. The shift of the annual water balance in the $F-\varphi$ space is a combination of the Budyko-type response in the deep groundwater zone and the quasi-energy-limited condition in the shallow groundwater zone. Shallow groundwater supplies excess evapotranspiration during dry years, leading to the $F>1$ cases. The occurrence of the $F>1$ cases depends on the proportion area of the shallow groundwater zone, the intensity of groundwater-dependent evapotranspiration and the catchment properties determining the Budykotype $F-\varphi$ relationship in the deep groundwater zone. Water utilization for irrigation may enhance this excess evapotranspiration phenomenon. The modified Budyko space with the effective precipitation incorporating the change in storage can force $F$ values below 1.0. However, the computation is complicated in dealing with the gain-loss feedback and uncertain with the inaccessible storage for the evapotranspiration process. The empirical formula proposed in this study for the standard Budyko space provides a straightforward method for predicting the changes in the annual water balance with the varying dryness.

\section{Data availability}

The hydrological data in the Yellow River basin, China, are provided by the Yellow River Conservancy Commission (YRCC, 2013) and distributed free of charge by the China National Earth System Science Data Sharing Infrastructure for registered users (http://www.geodata.cn/data/datadetails. html?dataguid=137744246250530\&docId=1834). The meteorological data products are available free of charge through the Climatic Data Center, China Meteorological Administration (CMA, 2012) (http://data.cma.cn/data/index/ 6d1b5efbdcbf9a58.html). 
Acknowledgements. This study is supported by the Program for New Century Excellent Talents in University (NCET) that was granted by the Ministry of Education, China, and partly supported by the Honor Power Foundation, UNESCO-IHE. The authors are grateful to the constructive comments from R. Donohue, F. Jaramillo and the other anonymous reviewers.

Edited by: R. Moussa

Reviewed by: R. Donohue, F. Jaramillo, and three anonymous referees

\section{References}

Alley, W. M.: On the treatment of evapotranspiration, soil moisture accounting, and aquifer recharge in monthly water balance models, Water Resour. Res., 20, 1137-1149, 1984.

Arora, V. K.: The use of the aridity index to assess climate change effect on annual runoff, J. Hydrol,, 265, 164-177, 2002.

Budyko, M. I.: Evaporation under natural conditions, Isr. Program for Sci. Transl., Jerusalem, Isreal, 1948.

Budyko, M. I.: The heat balance of the earth's surface, US Department of Commerce, Washington, D.C., USA, 1958.

Budyko, M. I.: Climate and life, Academic, New York, USA, 1974.

Chen, X. and $\mathrm{Hu}, \mathrm{Q}$.: Groundwater influences on soil moisture and surface evaporation, J. Hydrol., 297, 285-300, 2004.

Chen, X., Alimohammadi, N., and Wang, D.: Modeling interannual variability of seasonal evaporation and storage change based on the extended Budyko framework, Water Resour. Res., 49, 60676078, doi:10.1002/wrcr.20493, 2013.

Cheng, L., Xu, Z., Wang, D., and Cai, X.: Assessing interannual variability of evapotranspiration at the catchment scale using satellite-based evapotranspiration data sets, Water Resour. Res., 47, W09509, doi:10.1029/2011WR010636, 2011.

CMA (China Meteorological Administration): Monthly land surface climatic dataset in China, Climatic Data Center, National Meteorological Information Center, CMA, Beijing, China, available at: http://data.cma.cn/data/index/6d1b5efbdcbf9a58. html (last access: 9 July 2016) 2012.

Cohen, D., Person, M., Daannen, R.,Sharon, L., Dahlstrom, D., Zabielski, V., Winter, T. C., Rosenberry, D. O., Wright, H., Ito, E., Nieber, J., and Gutowski Jr., W. J.: Groundwater-supported evapotranspiration within glaciated watersheds under conditions of climate change, J. Hydrol., 320, 484-500, 2006.

Donohue, R. J., Roderick, M. L., and McVicar, T. R.: On the importance of including vegetation dynamics in Budyko's hydrological model, Hydrol. Earth Syst. Sci., 11, 983-995, doi:10.5194/hess11-983-2007, 2007.

Fan, J., Wang, Q., and Hao, M.: Estimation of reference crop evapotranspiration by Chinese pan, Transactions of the CSAE, 22, 14-17, 2006. (in Chinese)

Fernandez, W., Vogel, R. M., and Sankarasubramanian, A.: Regional calibration of a watershed model, Hydrol. Sci. J., 45, 689707, 2000

Fu, B. P.: On the calculation of the evaporation from land surface, Sci. Atmos. Sin., 5, 23-31, 1981. (in Chinese)

Gentine, P., D'Odorico, P., Lintner, B. R., Sivandran, G., and Salvucci, G.: Interdependence of climate, soil, and vegetation as constrained by the Budyko curve, Geophys. Res. Lett., 39, L19404, doi:10.1029/2012GL053492, 2012.

Gerrits, A. M. J., Savenije, H. H. G., Veling, E. J. M., and Pfister, L.: Analytical derivation of the Budyko curve based on rainfall characteristics and a simple evaporation model, Water Resour. Res., 45, W04403, doi:10.1029/2008wr007308, 2009.

Greve, P., Gudmundsson, L., Orlowsky, B., and Seneviratne, S. I.: Introducing a probabilistic Budyko framework, Geophys. Res. Lett., 42, 2261-2269, 2015.

Greve, P., Gudmundsson, L., Orlowsky, B., and Seneviratne, S. I.: A two-parameter Budyko function to represent conditions under which evapotranspiration exceeds precipitation, Hydrol. Earth Syst. Sci., 20, 2195-2205, doi:10.5194/hess-20-21952016, 2016.

Istanbulluoglu, E., Wang, T., Wright, O. M., and Lenters, J. D.: Interpretation of hydrologic trends from a water balance perspective: The role of groundwater storage in the Budyko hypothesis, Water Resour. Res., 48, W00H16, doi:10.1029/2010WR010100, 2012.

Jaramillo, F. and Destouni, G.: Developing water change spectra and distinguishing change drivers worldwide. Geophys. Res. Lett., 41, 8377-8386, 2014.

Jaramillo, F. and Destouni, G.: Local flow regulation and irrigation raise global human water consumption and footprint, Science, 350, 1248-1251, 2015.

Koster, R. D. and Suarez, M. J.: A Simple framework for examining the interannual variability of land surface moisture fluxes, J. Climate, 12, 1911-1917, 1999.

Li, W. and Sankarasubramanian, A.: Reducing hydrologic model uncertainty in monthly streamflow predictions using multimodel combination, Water Resour. Res., 48, W12516, doi:10.1029/2011WR011380, 2012.

Lv, J., Wang, X.-S., Zhou, Y., Qian, K., Wan, L., Derek, E., and Tao, Z.: Groundwater-dependent distribution of vegetation in Hailiutu River catchment, a semi-arid region in China, Ecohydrology, 6, 142-149, 2013.

Martinez, G. F. and Gupta, H. V.: Toward improved identification of hydrological models: A diagnostic evaluation of the "abcd" monthly water balance model for the conterminous United States, Water Resour. Res., 46, W08507, doi:10.1029/2009WR008294, 2010.

Mathevet, T., Michel, C., Andreassian, V., and Perrin, C.: A bounded version of the Nash-Sutcliffe criterion for better model assessment on large sets of basins, In: Large Sample Basin Experiments for Hydrological Model Parameterization: Results of the Model Parameter Experiment-MOPEX, IAHS Publ., 307, 211-218, 2006.

Mezentsev, V. S.: More on the calculation of average total evaporation, Meteorol. Gidrol., 5, 24-26, 1955.

Middleton, N. and Thomas, D. S. G.: World atlas of desertification, United Nations Environment Programme, Edward Arnold, 1992.

Nash, J. E. and Sutcliffe, J. V.: River flow forecasting through conceptual models part I - A discussion of principles, J. Hydrol., 10, 282-290, 1970.

Porporato, A., Daly, E. and Rodriguez-Iturbe, I.: Soil water balance and ecosystem response to climate change, Am. Nat., 164, 625632, 2004

Potter, N. J. and Zhang, L.: Interannual variability of catchment water balance in Australia, J. Hydrol., 369, 120-129, 2009. 
Renner, M., Seppelt, R., and Bernhofer, C.: Evaluation of waterenergy balance frameworks to predict the sensitivity of streamflow to climate change, Hydrol. Earth Syst. Sci., 16, 1419-1433, doi:10.5194/hess-16-1419-2012, 2012.

Roderick, M. L. and Farquhar, G. D.: A simple framework for relating variations in runoff to variations in climatic conditions and catchment properties, Water Resour. Res., 47, W00G07, doi:10.1029/2010WR009826, 2011.

Sankarasubramanian, A. and Vogel, R. M.: Annual hydroclimatology of the United States, Water Resour. Res., 38, 1083, doi:10.1029/2001WR000619, 2002.

Shi, C., Niu, K. Chen, T., and Zhou, X.: The study of pan coefficients of evaporation pans, Scientia Gepgrophica Sinica, 6, 305313, 1986. (in Chinese)

Sloto, R. A. and Crouse, M. Y.: HYSEP: a computer program for streamflow hydrograph separation and analysis, US Geological Survey Water-Resources Investigations Report 96-4040, 1996.

Thomas, H. A.: Improved methods for national water assessment, report, Contract WR 15249270, US Water Resour. Council, Washington, D.C., USA, 1981.

Vandewiele, G. L., Xu, C.-Y., and Ni-Lar-Win: Methodology and comparative study of monthly water balance models in Belgium, China and Burma, J. Hydrol., 134, 315-347, 1992.

Wang, D.: Evaluating interannual water storage changes at watersheds in Illinois based on long-term soil moisture and groundwater level data, Water Resour. Res., 48, W03502, doi:10.1029/2011WR010759, 2012.

Wang, D. and Tang, Y.: A one-parameter Budyko model for water balance captures emergent behavior in darwinian hydrologic models, Geophys. Res. Lett., 41, 4569-4577, doi:10.1002/2014GL060509, 2014.

Wang, T., Istanbulluoglu, E., Lenters, J., and Scott D.: On the role of groundwater and soil texture in the regional water balance: An investigation of the Nebraska Sand Hills, USA, Water Resour. Res., 45, W10413, doi:10.1029/2009WR007733, 2009.

Yang, D., Sun, F., Liu, Z., Cong, Z., and Lei, Z.: Interpreting the complementary relationship in non-humid environments based on the Budyko and Penman hypotheses, Geophys. Res. Lett., 33, L18402, doi:10.1029/2006g1027657, 2006.

Yang, D., Sun, F., Liu, Z., Cong, Z., Ni, G., and Lei, Z.: Analyzing spatial and temporal variability of annual water-energy balance in nonhumid regions of China using the Budyko hypothesis, Water Resour. Res., 43, W04426, doi:10.1029/2006wr005224, 2007.

Yang, H., Yang, D., Lei, Z., and Sun, F.: New analytical derivation of the mean annual water-energy balance equation, Water Resour. Res., 44, W03410, doi:10.1029/2007WR006135, 2008.
Yang, Z., Zhou, Y., Wenninger, J., and Uhlenbrook, S.: The causes of flow regime shifts in the semi-arid Hailiutu River, Northwest China, Hydrol. Earth Syst. Sci., 16, 87-103, doi:10.5194/hess16-87-2012, 2012.

Yeh, P. J.-F. and Famiglietti, J. S.: Regional Groundwater Evapotranspiration in Illinois, J. Hydrometeorol., 10, 464-478, 2009.

Yin, L., Zhou, Y., Huang, J., Wenninger, J., Zhang, E., Hou, G., and Dong, J.: Interaction between groundwater and trees in an arid site: Potential impacts of climate variation and groundwater abstraction on trees, J. Hydrol., 528, 435-448, 2015.

York, J. P., Person, M., Gutowski, W. J., and Winter, T. C.: Putting aquifers into atmospheric simulation models: An example from the Mill Creek Watershed, Northeastern Kansas, Adv. Water Res., 25, 221-238, 2002.

YRCC (Yellow River Conservancy Commission): Soil and Hydrology and Sediment of the Yellow River Basin, Data Sharing Infrastructure of Earth System Science_Data Sharing Infrastructure of Loess Plateau, Beijing, China, available at: http://www.geodata.cn/data/datadetails.html?dataguid= 137744246250530\&docId=1834 (last access: 9 July 2016), 2013.

Zhang, L., Dawes, W. R., and Walker, G. R.: Response of mean annual evapotranspiration to vegetation changes at catchment scale, Water Resour. Res., 37, 701-708, doi:10.1029/2000wr900325, 2001.

Zhang, L., Hickel, K., Dawes, W. R., Chiew, F. H. S., Western, A. W., and Briggs, P. R.: A rational function approach for estimating mean annual evapotranspiration, Water Resour. Res., 40, W02502. doi:10.1029/2003WR002710, 2004.

Zhang, L., Potter, N., Hickel, K., Zhang, Y., and Shao, Q.: Water balance modeling over variable time scales based on the Budyko framework - Model development and testing, J. Hydrol., 360, 117-131, doi:10.1016/j.jhydrol.2008.07.021, 2008.

Zhou, Y., Wenninger, J., Yang, Z., Yin, L., Huang, J., Hou, L., Wang, X., Zhang, D., and Uhlenbrook, S.: Groundwater-surface water interactions, vegetation dependencies and implications for water resources management in the semi-arid Hailiutu River catchment, China - a synthesis, Hydrol. Earth Syst. Sci., 17, 2435-2447, doi:10.5194/hess-17-2435-2013, 2013.

Zhou, Y., Yang, Z., Zhang, D., Jin, X., and Zhang, J.: Intercatchment comparison of flow regime between the Hailiutu and Huangfuchuan rivers in the semi-arid Erdos Plateau, Northwest China, Hydrolog. Sci. J., 60, 688-705, 2015. 